\title{
Structure and distribution of the Notch protein in developing Drosophila
}

\author{
Simon Kidd, Mary K. Baylies, Gregory P. Gasic, ${ }^{1}$ and Michael W. Young \\ Howard Hughes Medical Institute and Laboratory of Genetics, The Rockefeller University, New York, New York 10021 USA
}

\begin{abstract}
Antibodies to Notch show that it is a stable, high-molecular-weight transmembrane glycoprotein, with epidermal growth factor (EGF)-like elements exposed on the cell surface. The protein is phosphorylated variably on serines of the cytoplasmic domain. Individual Notch polypeptide chains appear to be associated with one another by disulfide bonds, suggesting that homotypic interaction of these proteins is required for function. Immunocytochemistry has revealed striking features of Notch expression that might clarify its function: Cells of the ventral neurogenic ectoderm become conspicuously labeled with the protein prior to embryonic neurogenesis, and Notch appears to be associated with cells destined for both neural and epidermal lineages. High levels of Notch become restricted to neuroblasts as they delaminate from the embryonic ectoderm and are apposed to mesoderm. Mesodermal cells express Notch also, suggesting a possible involvement in neurogenesis, or an unknown role in mesoderm differentiation. In larvae and pupae, a correlation of expression and neuroblast mitotic activity is seen for many cells. Notch produced by a dividing neuroblast may persist on derivative cells, including terminally differentiated neurons and nerve processes. In the larval eye imaginal disk, strong Notch expression appears in the morphogenetic furrow, uniformly on cell surfaces as they cluster to form ommatidia. Expression persists on ommatidia after release from the furrow. These patterns suggest a role for Notch in position-dependent development in both initiation and maintenance of cell-surface interactions. In the eye and embryonic ectoderm, uniform expression on cells interacting to produce different developmental lineages from a single primordium suggests that Notch alone may not be sufficient to elaborate cell fates.
\end{abstract}

[Key Words: Immunocytochemistry; neurogenesis; hypoderm development; position-dependent cell differentiation; maintenance of cell fate]

Received April 12, 1989; revised version accepted June 2, 1989.

During insect embryogenesis, cells of the neurogenic ectoderm become either neuroblasts or epidermoblasts. The choice of cell fate involves, at least in part, intercellular interactions (for review, see Technau 1987). For example, cell ablation studies have shown that neuroblasts inhibit neighboring nonneural cells directly from expressing a latent potential to become neuroblasts themselves (Doe and Goodman 1985a,b). In Drosophila, a study of the genetic control of ectoderm development has been initiated through the recovery of neurogenic mutants (Lehmann et al. 1983). These overproduce neuroblasts at the expense of nonneural ectoderm, and thus generate, on a larger scale, phenotypes comparable to those derived by specific neuroblast ablations.

The best characterized mutants in this series are associated with complete loss-of-function at the Notch locus. From its DNA sequence, Notch appears to encode a $288-\mathrm{kD}$ protein, the structure of which is dominated by a 36 -fold tandem repetition of a cysteine-rich peptide related to epidermal growth factor (EGF) (Wharton et al.

Present address: Section of Molecular Neurobiology, Yale University School of Medicine, New Haven, Connecticut 06510 USA.
1985; Kidd et al. 1986). This motif also is found in certain clotting factors, receptors, substrate adhesion molecules, and some other growth factors. In Notch, none of these repeats is identical. Genetic and molecular analyses of mutations affecting this domain of the protein indicate that differentiation of function exists among the EGF-like repeats (Kelley et al. 1987). These studies indicate further that genetic interactions among Notch alleles, and among Notch and unlinked neurogenic loci, can be modified by amino acid substitutions affecting specific EGF-like repeats at Notch (Hartley et al. 1987; Kelley et al. 1987). All of this suggests that Notch contributes to a system of cell-cell interactions dictating ectoderm fate.

In this paper the Notch protein is characterized, using antibodies generated against TrpE-Notch fusion proteins. Biochemical and immunocytochemical studies indicate a stable association of the protein with cell membranes. Notch is found on several cell types, both before and after terminal differentiation. The distributions reported in this paper are consistent with a role in position-dependent development through both establishment and maintenance of specialized contacts among differentiating cells. 


\section{Results}

Suitable antigens for generating antibodies against Notch were prepared by inserting restriction fragments into appropriate pATH (Dieckmann and Tzagoloff 1985) expression vectors. These fragments and the region of the putative protein to which they correspond are diagramed in Figure 1a. After affinity purification (see Materials and methods), each of five antibodies detected a protein in embryonic extracts (Fig. 1b; BP reactivity is illustrated in Fig. $2 \mathrm{~b}$ ) which migrates, under reducing conditions, more slowly than myosin $(200 \mathrm{kD})$. Subsequent analyses showed that the protein has a molecular weight of $\sim 350 \mathrm{kD}$. As this protein is precipitated with the immune serum used to derive each affinity purified antibody, but not with corresponding preimmune sera (data not shown), the specificity of the Notch antibodies is confirmed further. Protein having the same molecular weight also was detected in Drosophila cultured Kc cells (Echalier and Ohanessian 1970) with antibodies directed against nonoverlapping domains of Notch (see below; Fig. 2).

The $350-\mathrm{kD}$ protein has a developmental profile of expression (Fig. 1c) similar to that previously found for Notch RNA (Kidd et al. 1983). This antigen also is absent in Notch-deficient embryos (Fig. 1c,d). From these results it was concluded that the $350-\mathrm{kD}$ protein is a product of the Notch locus.

Sequence analysis raised the possibility that the Notch protein is glycosylated (Wharton et al. 1985; Kidd et al. 1986). Figure 2 shows that the $350-\mathrm{kD}$ antigen, from cultured cells or embryos, reacts with both Concanavalin A (Con A) and wheat germ agglutinin (WGA). Figure 2a shows that Western blots of immunoprecipitated Notch antigen can be visualized with the lectin Con A. Moreover, as shown in Figure $2 b$, when primary embryonic cells are treated with tunicamycin, which blocks $\mathrm{N}$-glycosylation, the antigen no longer binds WGA and is reduced slightly in size to $\sim 325 \mathrm{kD}$. The antigen derived from tunicamycin-treated cells still migrates more slowly than would be expected from sequence analysis. As Notch lacks characteristic sites for $O$-glycosylation, aberrant electrophoretic mobility might be the result of phosphorylation (see below), its unusual amino acid sequence, or an unknown modification.

Notch accumulates as a stable, high-molecular-weight protein

EGF-like sequences have been identified in several proteins of diverse origins. In some of these proteins, such as the EGF precursor, processing occurs and EGF-like peptides are released to provide biological activity (Gray et al. 1983; Scott et al. 1983; Doolittle et al. 1984). Other EGF-related proteins, such as certain adhesion molecules (Lawler and Hynes 1986; Sasaki et al. 1987; Jones et al. 1988; Montell and Goodman 1988; Bevilacqua et al. 1989; Mann et al. 1989; Siegelman et al. 1989|, or receptors such as that for LDL (Russell et al. 1984), are composed of multiple copies of the peptide sequence which are not released from the nascent protein. The fate of newly synthesized Notch protein was analyzed by a pulse-chase experiment (Fig. 3). As a control, Figure 3a shows that, in vitro, primary embryonic cells (see Materials and methods) are able to process the Drosophila insulin receptor (IR) precursor into mature IR consisting of $\alpha$ - and $\beta$-subunits. Cells were labeled for 90 $\mathrm{min}$ in ${ }^{35} \mathrm{~S} \mid$ cysteine and $\left[{ }^{35} \mathrm{~S}\right]$ methionine, and processing of labeled protein was followed over the course of a 270min chase. Labeled IR precursor, which was recovered by immunoprecipitation (see Materials and methods), declined in abundance severalfold, indicating that intracellular pools of labeled amino acids are eliminated effectively during the chase. In contrast, radioactively labeled $\alpha$ and $\beta$ IR subunits did accumulate.

Figure $3 \mathrm{~b}$ illustrates that labeled Notch proteins, produced as described above for IR detection, are stable over the course of the 270-min chase (see Fig. 3, legend). Additionally, no processed products are detected with antibodies against either putative intracellular (NR) or extracellular (BPC) domains of the protein. A significant fraction of the initially labeled Notch protein is detected at the close of the chase (Fig. 3, legend), suggesting that individual molecules of Notch may be stable for a major portion of embryogenesis and perhaps over the course of several cell divisions. With the caveat that the data are derived from dissociated cells incorporating labeled amino acids in vitro, the results suggest that at least in the majority of embryonic cells, Notch functions as an unprocessed protein.

\section{EGF-like repeats are oriented externally on a transmembrane Notch protein}

Sequence analysis suggested that Notch might span the cell membrane (Wharton et al. 1985; Kidd et al. 1986). As indicated in Figure la, antisera were raised to epitopes on either side of a putative transmembrane domain of the protein (see Fig. la). Membrane association and orientation of the protein were determined directly by digesting intact embryonic or cultured Drosophila cells with trypsin, which should have cleavage sites throughout the protein. In Kc-cultured cells, protease treatment results in loss of antigen detected with antibody directed against EGF-repeats (BPC, Fig. $4 \mathrm{f}-\mathrm{j}$ ), but a novel, $110-\mathrm{kD}$ protein is generated which reacts with antibody directed against the putative cytoplasmic domain (NR, Fig. 4a-e). This is not an intrinsically trypsin-resistant fragment because permeablization of the cells with $0.1 \%$ Triton X-100 at the same time results in its absence (data not shown). The 110-kD fragment is produced and detected by this method when primary embryonic cells are trypsinized (see Fig. 5c). As the EGF-like repeats are susceptible to trypsin, they must be exposed on the surface of the cell. Given the size of the trypsin-insensitive fragment $(110 \mathrm{kD}$, Fig. $4 \mathrm{~d}, \mathrm{e})$, and its specific recognition by antibody directed against carboxyl-terminal segments of the predicted protein, the Notch protein appears to cross the membrane at the position predicted from sequence analysis (see also map, Fig. 1). 

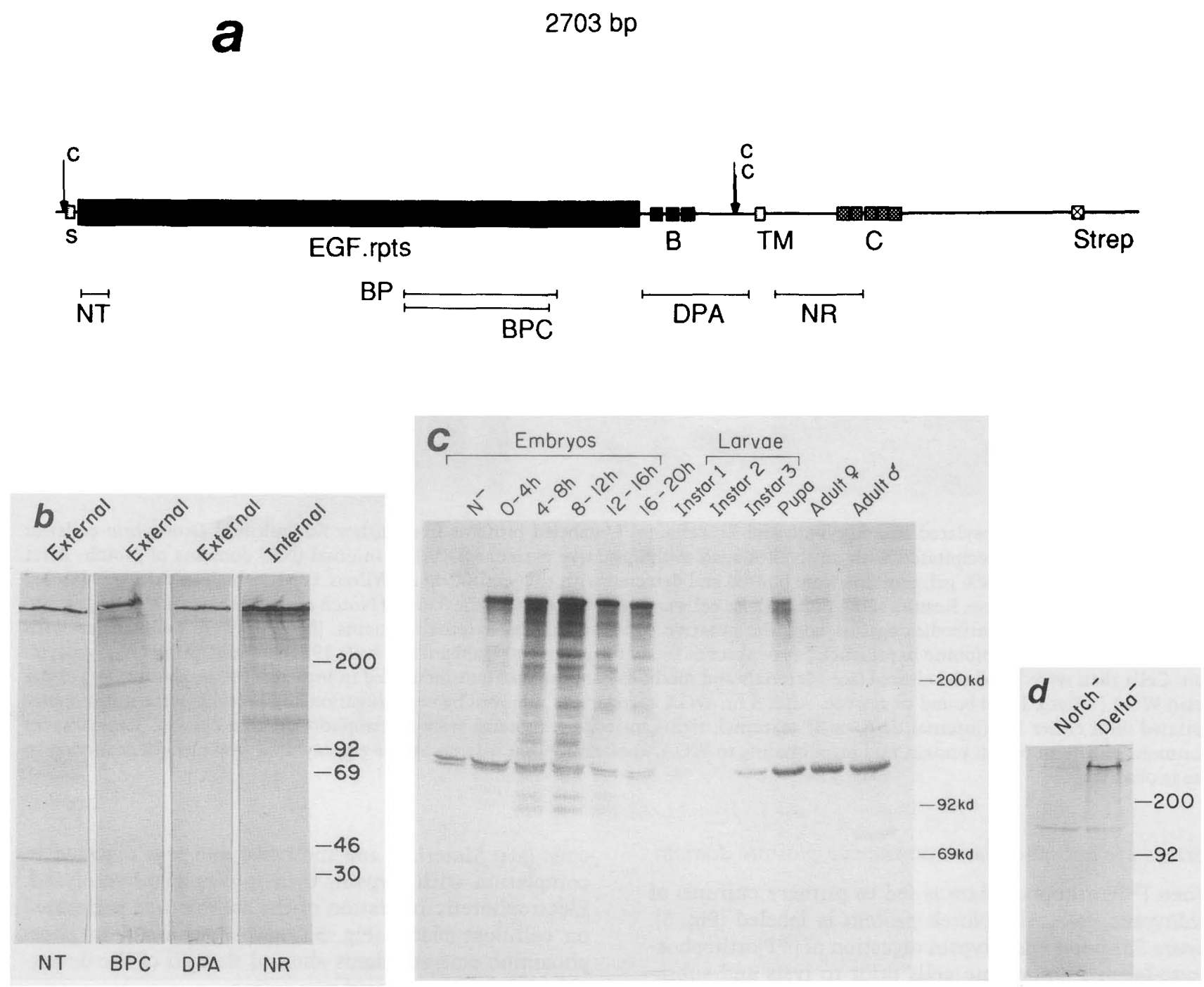

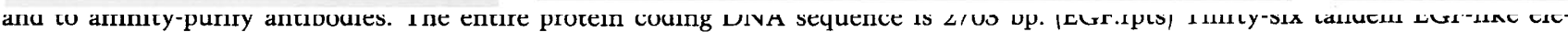
ments; (B) B-type cysteine-rich repeats; (C) C-type tandem repeats; (c) cysteines possibly involved in interchain disulfide bonding; $(\mathrm{s})$ signal sequence; (TM) transmembrane sequence; (Strep) polyglutamine repeat (see also, Kidd et al. 1986). NT, BP, BPC, DPA, and NR show locations of cloned DNA used to produce fusion proteins. Amino acid and nucleotide coordinates for segments are given in Materials and methods. (b) Immunoblot of embryonic proteins fractionated on a 3-12.5\% gel. After transfer of proteins, the filter was cut into strips and reacted with each antibody. Primary antibody was detected with an alkaline phosphatase-conjugated second antibody. Label above each lane refers to location of segment of Notch protein used to generate each antibody relative to putative orientation of Notch in cell membrane from sequence analysis. Antibodies detect a common antigen of $350 \mathrm{kD}$ (see text). The smear running below $350 \mathrm{kD}$ to approximately $100 \mathrm{kD}$ (lane NR) probably reflects degradation of the external domain of Notch during isolation of cells, and is not seen with NR in protein blots from Notch-deficient embryos (data not shown, but see 1c, below). (c) Developmental profile of Notch expression detected with NR antibody is shown. Each lane contains $90 \mu \mathrm{g}$ of total protein fractionated on a $4-10 \%$ gel (see Materials and methods). For embryo samples, numbers refer to time after egg laying when embryos were collected. Three larval instars, unstaged pupal proteins, and adults divided by sex are shown. (Lane $\left.N^{-}\right)$Proteins from $D f(1) N^{66 i 25}$ embryos are shown, which lack $70 \%$ of the Notch transcription unit (Kidd et al. 1983). NR antibodies bound to blots $b$ and $c$ were detected using a biotinylated second antibody followed by streptavidin-conjugated alkaline phosphatase. This treatment results in nonspecific labeling of two $120-\mathrm{kD}$ proteins, that also are seen in the absence of primary antibody and thus, are the result of this particular detection system. Minor antigens of $\sim 325 \mathrm{kD}$ are often seen in blots with each of the antibodies, and probably represent degradation products, as their abundance can be increased substantially by eliminating protease inhibitors. The minor antigens have not been characterized further. $(d)$ Notch proteins from Notch and Delta mutant embryos, both of which have lethal neurogenic phenotypes. The Notch mutant was $D f(1) N^{66 i 25}$ (described above). The Delta mutant is $D l^{x}$, which has an extreme neurogenic phenotype, but the molecular nature of the mutant is not known (Craymer 1984). Enriched samples of dying, mutant embryos were obtained by collecting 0 - to 6-hr-old progeny of balanced lethal stocks, and aging these for $24 \mathrm{hr}$. The resulting mixture of wild-type larvae and mutant embryos was separated largely by submersing in $1 \mathrm{M}$ sucrose with $0.1 \%$ Triton. After most buoyant larvae were removed, embryos were collected by rinsing with water. Detergent-solubilized proteins were loaded on a 3-12.5\% gel, and Notch was detected with NR antibody. Similar results were obtained with the other antibodies (data not shown). The 350-kD antigen is almost completely absent in the sample enriched for Notch mutant embryos, but is present in Delta mutant embryos of a similar age and phenotype. Residual Notch protein in the $\mathrm{Notch}^{-}$lane is the result of contaminating larvae. 

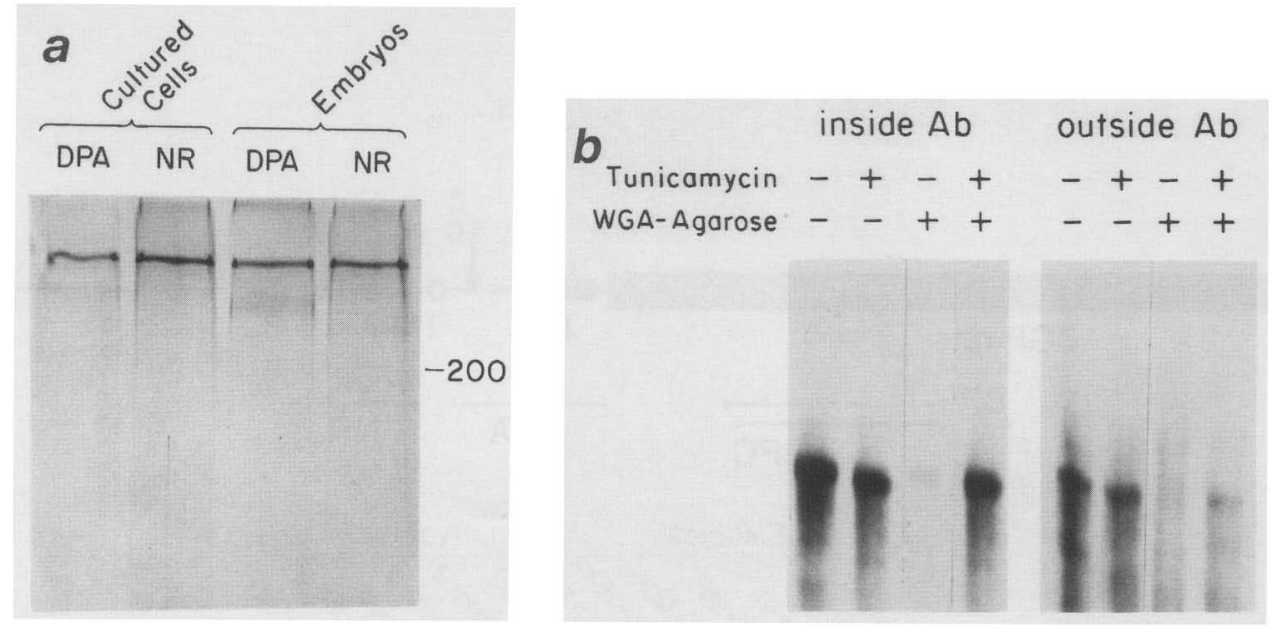

Figure 2. Notch is glycosylated in embryonic and Kc cells. $|a|$ Unlabeled proteins from either Kc (cultured Drosophila cells) or embryos were immunoprecipitated with antibodies against the putative external (DPA) or internal (NR) domains of Notch. After electrophoresis though a $4 \%$ gel, proteins were blotted and detected with the lectin Con A (Wilcox 1986), which in turn was labeled with horseradish peroxidase. Results show that both Kc cells and embryos contain the $350-\mathrm{kD}$ Notch antigen, that it is a glycoprotein, and that it reacts with antibodies against both the putative cell internal and external domains. $(b)$ Cells were radiolabeled with $\left[{ }^{35} S\right]$ cysteine and ${ }^{35}$ S $\mid$ methionine in presence (+) or absence (-) of tunicamycin (Hubbard and Ivatt 1981), which inhibits $N$-glycosylation. Cells then were lysed and cleared (see Materials and methods), and supernatant incubated in presence $(+\mid$ or absence $(-)$ of the lectin WGA (Wilcox 1986) bound to agarose. After $5 \mathrm{hr}$, WGA agarose was removed by centrifugation and proteins were immunoprecipitated with either NR (internal, left), or BP (external, right) antibodies. Proteins were electrophoresed on a $4 \%$ gel. Tunicamycin treatment results in Notch protein no longer binding to WGA, confirming that it is no longer glycosylated, and a slight reduction in size is observed.

\section{Serines are phosphorylated on the cytoplasmic domain}

When $\left[{ }^{32} \mathrm{P}\right]$ orthophosphate is fed to primary cultures of embryonic cells, the Notch protein is labeled (Fig. 5). Figure $5 \mathrm{~b}$ shows that trypsin digestion of $\left[{ }^{32} \mathrm{P}\right]$ orthophosphate-labeled embryonic cells prior to lysis and subsequent immunoprecipitation with an antibody directed toward the internal segment of the Notch protein leads to the recovery of a $110-\mathrm{kD}$ labeled protein fragment. Thus, at least some phosphorylation is mapped to the cytoplasmic domain of Notch. A Western blot of the same preparation of the $110-\mathrm{kD}$ protein fragment, visualized by antibody staining, is shown in Figure $5 \mathrm{c}$. Because autoradiography detects a smear while antibody labeling detects a discrete $110-\mathrm{kD}$ protein, this pattern may reflect multiple phosphorylations of Notch. It has been shown in other systems (Pognonec et al. 1988) that phosphorylation decreases the mobility of a protein and can result, therefore, in multiple bands on the autoradiograph. The difference between the immunoblot and autoradiograph suggests that only a minor fraction of the Notch protein is phosphorylated, with most of Notch detected as a single band on the blot. Additional evidence for multiple phosphorylation sites has been obtained from protease V8 digestion of ${ }^{32} \mathrm{P}$-labeled Notch protein; three phosphopeptides are visible over a broad range of protease concentrations (data not shown), suggesting that there are multiple phosphorylatable sites per polypeptide chain.

To characterize this phosphorylation further, phosphoamino acid analysis was performed. ${ }^{32} \mathrm{P}$-Labeled Notch protein was immunoprecipitated from embryonic cells (see Materials and methods) and was digested to completion with trypsin; then it was acid-hydrolyzed. Electrophoretic migration of the sample was performed on cellulose plates (Fig. 5a) and comparison to phosphoamino acid standards showed that all of the detectable, labeled amino acid was serine.

\section{Unusual electrophoretic mobility in response to reducing agents}

From genetic complementation studies of mutations affecting certain EGF-like repeats, it has been proposed that individual Notch polypeptide chains must interact with each other to function (Kelley et al. 1987). Figure 6a shows the result of fractionating Notch in the presence of increasing amounts of dithiothreitol (DTT). Upon mild reduction, the mobility of Notch is increased to that expected for a protein somewhat larger than 200 $\mathrm{kD}$, indicating that, in vivo, Notch is likely to be associated with another protein by disulfide bonds. The shift in mobility is reversed by further increase in DTT concentration. The second phase of the antigen's response is attributed most easily to reduction of intramolecular disulfide bonds within the separated Notch polypeptide chains. Breakage of intrachain linkages would be expected to decrease rather than increase mobility as a result of unfolding of the protein. In this instance the effect of intrachain disulfide bonding on electrophoretic mobility is expected to be substantial as a result of the number of cysteine residues composing the EGF-like elements of the protein. As indicated in Figure 6a, compa- 

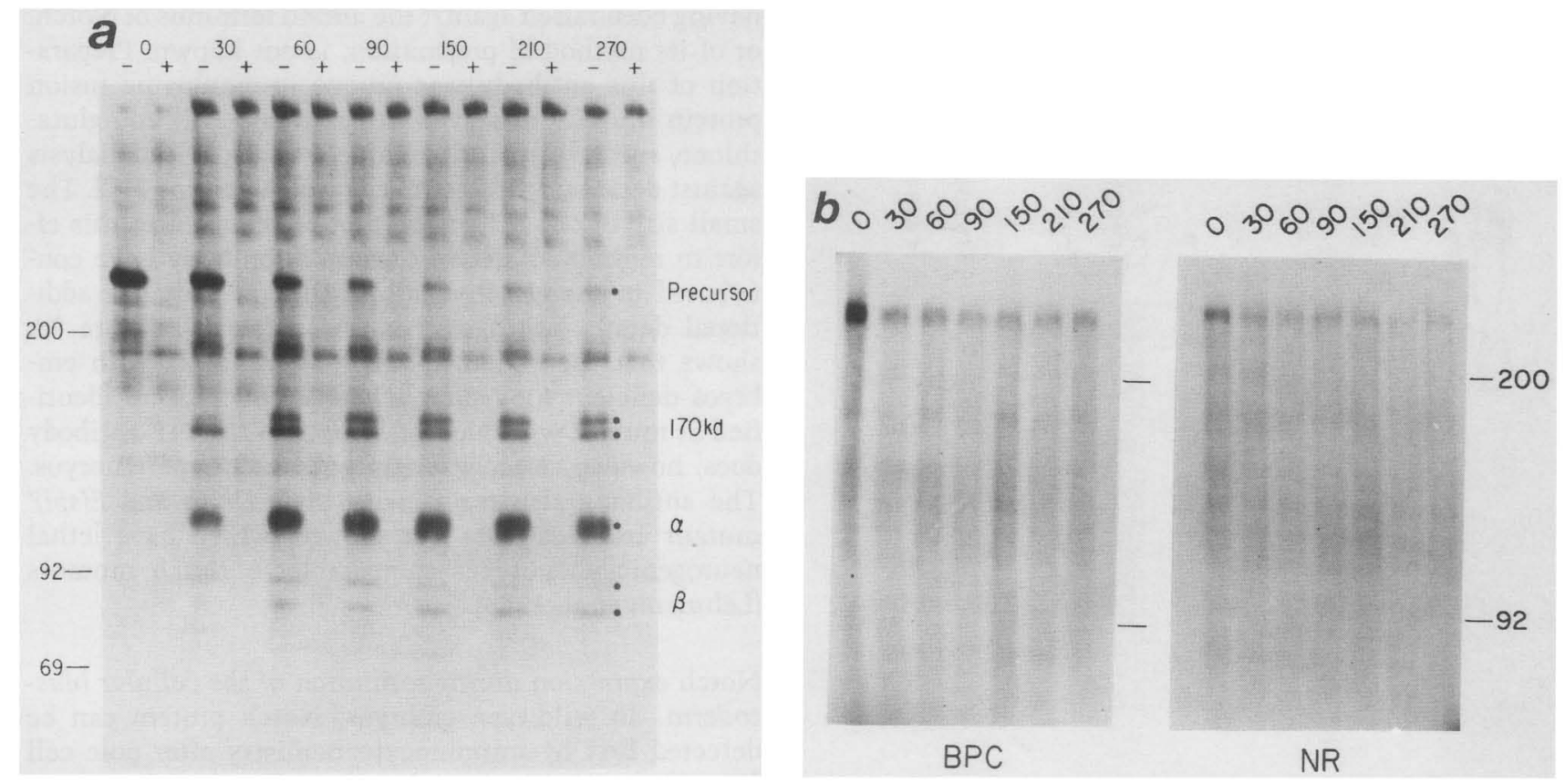

Figure 3. Notch is stable and unprocessed in the majority of dissociated embryonic cells. (a) Embryonic cells were labeled with ${ }^{[35}$ S $]$ methionine and ${ }^{35}$ S $]$ cysteine as described in Materials and methods. Cells then were chased with unlabeled amino acids for various periods of time (indicated above the lanes in $\mathrm{min}$ ). After lysis proteins were immunoprecipitated with an antibody against the Drosophila insulin receptor (kindly provided by R. Fernandez- Almonacid and O. Rosen) in the presence $(+)$ or absence $(-\mid$ of competing peptide. Locations of the unprocessed precursor and its processed products $(\alpha$ and $\beta)$ together with a 170-kD, derivative protein are indicated (after Fernandez-Almonacid and Rosen 1987). (b) Proteins from lysates as in $a$ were immunoprecipitated with antibodies against either putative external (BPC) or internal (NR) domains of Notch. In contrast to results seen for IR, no processing product accumulates for Notch. In $b$ the 0 time point for BPC was probably double-loaded /compare to 0 point from same cells precipitated with NR). Examples shown represent one of three experiments; no consistent differences between 0 and 30 min time points were observed in the series. BPC and NR immunoprecipitates were analyzed by further SDS-PAGE and also by electrophoresis on SDSurea gels which together resolve proteins down to approximately $2 \mathrm{kD}$. However, no additional labeled material was detected (data not shown). Abundance of full-length labeled protein at $270 \mathrm{~min}$ was $>50 \%$ of value at $0 \mathrm{~min}$ for all data not shown. The results of trypsin exposure (see Fig. 4) suggest that the proteolytic fragment comprising the internal domain of Notch would be stable if generated by processing.

rable DTT-induced changes in Notch protein mobility are observed in embryos and pupae.

The above experiment suggests that Notch is disulfide bonded to another protein of at least $150 \mathrm{kD}$ (the difference between its smallest size and its unreduced molecular weight). To detect any protein(s) associated with
Notch, embryonic cells were labeled with either $\left[{ }^{35} S\right]$ methionine, $\left[{ }^{35} S\right]$ cysteine (data not shown), or $\left[{ }^{32} \mathrm{P}\right]$ orthophosphate. Unreduced Notch protein complexes were immunoprecipitated and then electrophoresed either in the absence of reducing agent, or in the presence of fully reducing concentrations of DTT. The immunoprecipi-

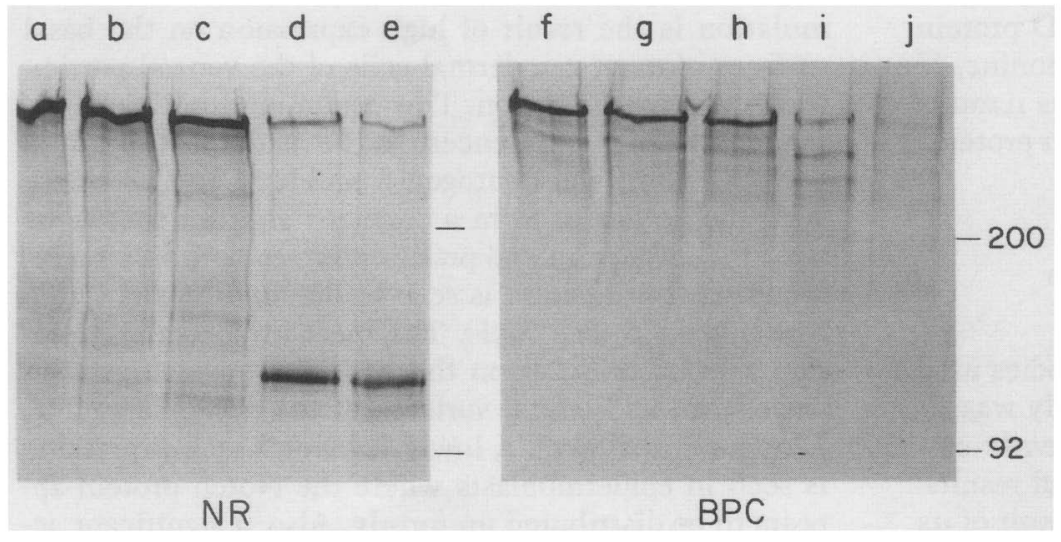

Figure 4. Orientation of Notch in the cell membrane. Kc cells were incubated with no additions (lanes $b$ and $g), 1 \mathrm{mg} / \mathrm{ml}$ of trypsin plus 2 $\mathrm{mg} / \mathrm{ml}$ of soya bean trypsin inhibitor (lanes $c$ and h), $10 \mu \mathrm{g} / \mathrm{ml}$ of trypsin (lanes $d$ and $i), 1 \mathrm{mg} / \mathrm{ml}$ of trypsin (lanes $e$ and $j$ ) for $15 \mathrm{~min}$, or lysed immediately (lanes $a$ and ff. After pelleting and lysis, cells were immunoprecipitated with either antibody against putative cytoplasmic (NR) or external (BPC) domain. Each immunoprecipitate was fractionated on a $4 \%$ gel and immunoblotted using the same antibody. Results show that EGF-like sequences are sensitive to trypsin digestion, whereas $110 \mathrm{kD}$ from the carboxyl terminus of Notch is not (see also Materials and methods). 


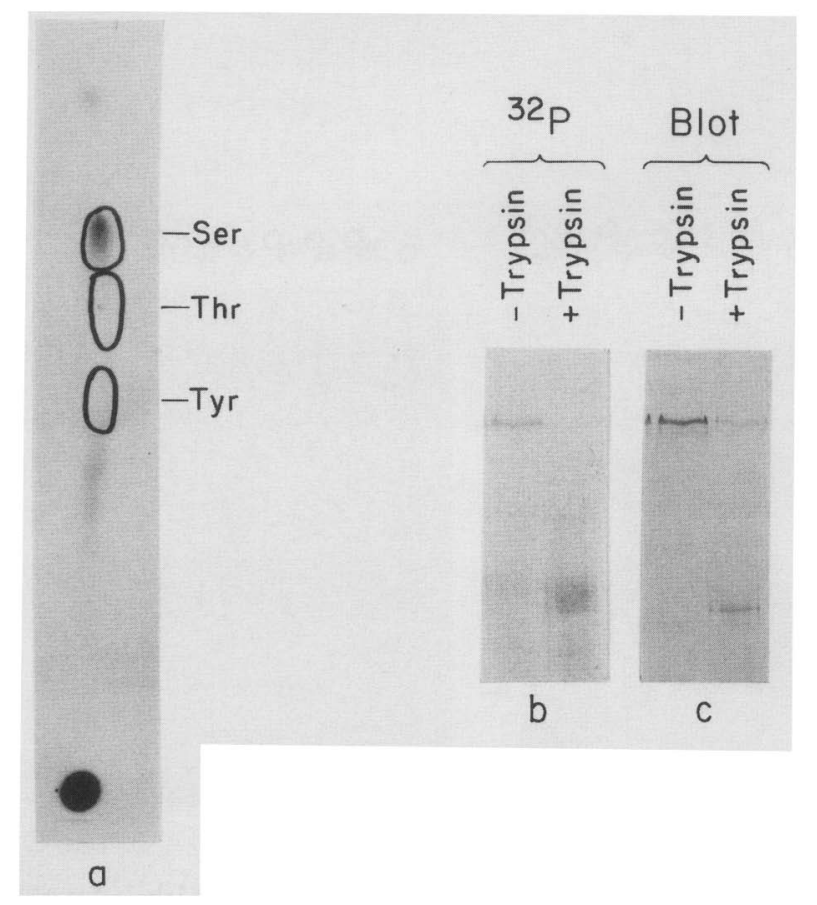

Figure 5. Notch is phophorylated on serine residues of the cytoplasmic domain. (a) Embryonic cells were labeled with [22P]orthophosphate (Materials and methods), and Notch proteins were immunoprecipitated with NR, gel-purified, and cochromatographed with unlabeled phosphoamino acid standards on a TLC plate. Standards were detected by ninhydrin staining and positions on the plate are indicated by labeled circles. Autoradiography shows that ${ }^{32} \mathrm{P}$-labeled amino acid in Notch comigrates with phophoserine. Chromatographic analysis was generously provided by S. Kornbluth. $\left\langle\left. b\right|^{32} \mathrm{P}\right.$-Labeled embryonic cells were untreated or trypsinized $(10 \mu \mathrm{g} / \mathrm{ml}$ for 15 $\mathrm{min}$ ), lysed, and immunoprecipitated with NR antibody. After electrophoresis through a $4 \%$ gel, proteins were blotted onto nitrocellulose and autoradiographed to detect ${ }^{32} \mathrm{P}$-labeled proteins. (c) Blot in $b$ was reacted with NR antibody which, in contrast to the autoradiograph of $b$, which detects a smear near 110 $\mathrm{kD}$, detects a discrete protein fragment of $110 \mathrm{kD}$.

tates were then analyzed by autoradiography (Fig. 6b). A single, high-molecular-weight antigen is visible in autoradiographs of both the reduced and unreduced samples. This indicates that Notch and the protein bound to it comigrate, and undergo the same mobility change when reduced, or that Notch is bound to $a \geqslant 150-\mathrm{kD}$ protein that is not labeled with either cysteine, methionine, or orthophosphate. As the latter possibility seems remote, the results strongly suggest that pairs of Notch proteins are always associated by disulfide bonds.

\section{Immunocytochemistry of the Notch protein in developing embryos}

Specificity of the antibody Each of the antibodies used to characterize the Notch protein biochemically was allowed to react with whole mounts of Drosophila embryos. Only one, antibody NT, gave meaningful results. Whether success with this antibody was the result of its having been raised against the amino terminus of Notch, or of its method of preparation, is not known. Preparation of this antibody was unique in employing fusion protein initially dissolved in guanidine $\mathrm{HCl}$ and glutathione, and subsequently refolding by sequential dialysis against decreasing concentrations of guanidine $\mathrm{HCl}$. The small size of the NT fusion protein, coupled to this effort to reestablish native conformation, may have contributed to the effectiveness of the antibody (for additional details, see Materials and methods). Figure 7A shows that the NT antibody does not react with embryos deficient for Notch. These embryos were identified as mutant with Nomarski optics. The NT antibody does, however, react strongly with wild-type embryos. The antibody also reacts with both Delta and $E(s p l)^{r}$ mutant embryos (data not shown), which have lethal neurogenic phenotypes comparable to Notch mutants (Lehmann et al. 1983).

Notch expression during formation of the cellular blastoderm In wild-type embryos, Notch protein can be detected first by immunocytochemistry after pole cell formation. At this stage Notch is distributed more or less uniformly across the embryo, with the exception that pole cells do not contain the protein (Fig. 7B, center). During blastoderm formation (i.e., as inward growth of cell membranes occur; Fig. 7B, left and right) this pattern persists: All of the evolving somatic cells express Notch, and the protein becomes more abundant. At higher magnifications (data not shown), Notch appears to be linked distinctly to cell membranes.

Notch labels the ventral neurogenic ectoderm and forms a border separating mesoderm and ectoderm during gastrulation and neurogenesis With the onset of gastrulation, Notch expression rises in two bands of cells, running along either side of the ventral furrow (Fig. $7 \mathrm{Cl}$. Each band is approximately three cells wide. These two bands presumably correspond to a portion of the neurogenic region. When viewing whole mounts (e.g., Fig. 7C) in a different plane of focus, the protein seems to be most abundant below the embryo surface. At the beginning of germ-band elongation, Notch accumulates at the junction of the ectoderm and underlying mesoderm (Fig. 7D). Inspection of a number of comparably staged embryos (data not shown) indicates that the accumulation is the result of high expression on the basal surfaces of most ectodermal cells of the ventral portion of the neurogenic region. This accumulation intensifies as neurogenesis commences. As the neuroblasts begin to segregate from the neurogenic ectoderm and associate with each other to form a coherent stratum that separates the mesoderm and presumptive epidermis, a corresponding stratification is seen in the distribution of the Notch protein (Fig. 7E,F). The most intense accumulation appears to occur on the basal (in association with mesoderm) and lateral surfaces of the neuroblasts (Fig. $7 E_{;}$data not shown). A lower level of Notch expression is seen in epidermoblasts where the Notch protein appears to be distributed uniformly. Also, a significant ac- 

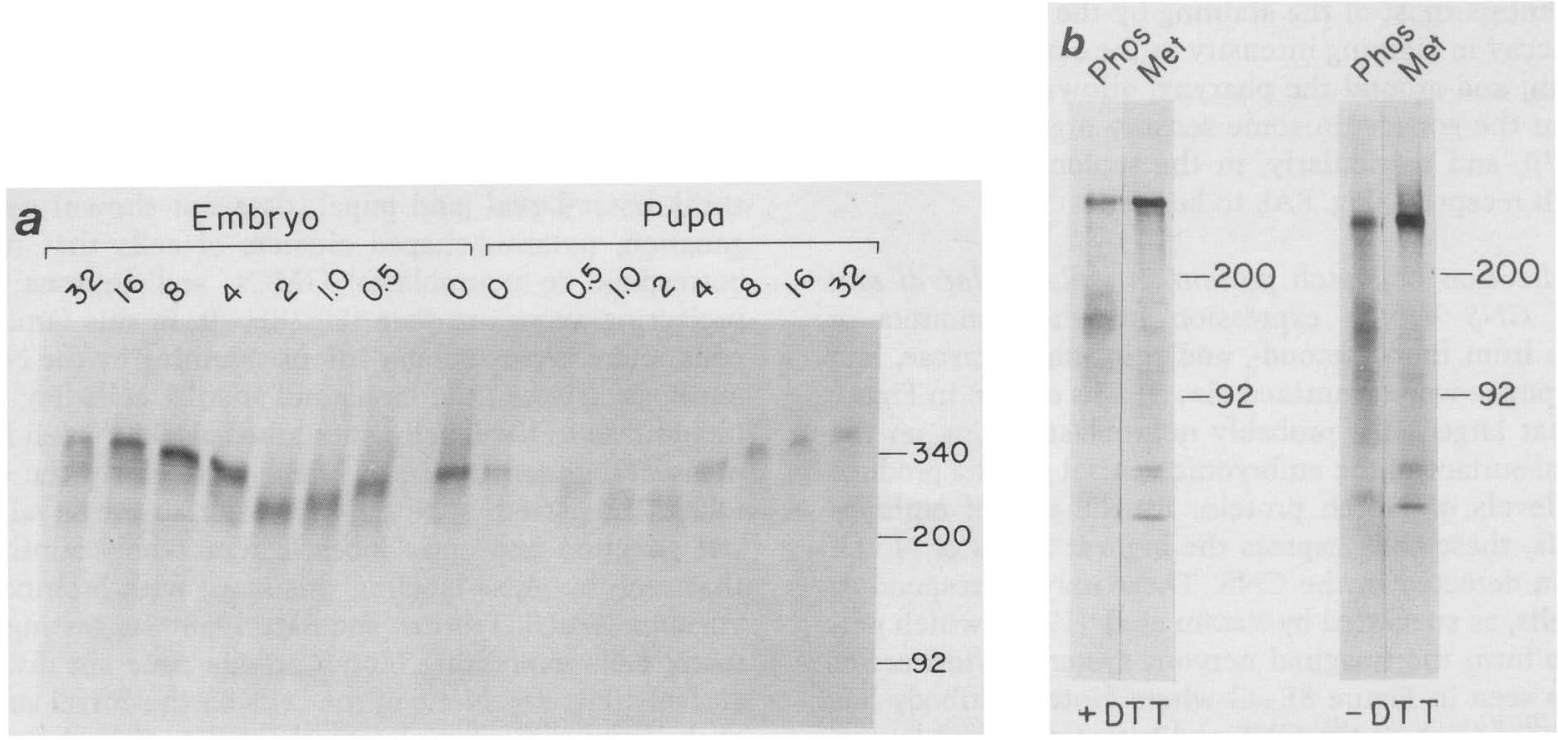

Figure 6. Response of the Notch protein to reducing agents. (a) Total proteins from either embryos $(300 \mu \mathrm{g})$ or pupae (200 $\mu \mathrm{g})$ were isolated in the presence of iodoacetamide (IAA) and then electrophoresed through a 3-5\% linear gradient gels in the absence or presence of increasing concentrations (indicated above each lane in $\mathrm{mM}$ ) of DTT. After blotting, Notch was detected with NR antibody. Minimum apparent molecular weight under reducing conditions measured over several experiments is $\sim 200 \mathrm{kD}$. The experiment shown in this figure shows slightly slower mobility. $(b)$ Embryonic cells radiolabeled with either [32P]orthophosphate $(\mathrm{marked}$ Phos) or ${ }^{35}$ S]methionine (marked Met) were lysed in the presence of iodoacetamide and immunoprecipitated with the NR antibody. After boiling for $5 \mathrm{~min}$ either in $10 \mathrm{~mm}$ IAA (lanes - DTT) or $0.1 \mathrm{M} \mathrm{DTT} \mathrm{(lanes} \mathrm{+DTT),} \mathrm{proteins} \mathrm{were} \mathrm{fractionated} \mathrm{through} \mathrm{a} \mathrm{3-12.5 \%}$ linear gradient gel and detected by autoradiography.

cumulation of Notch protein seems to be distributed throughout the mesoderm (Fig. 7E). Notch expression also can be seen elsewhere in the embryo at this stage: it is found in the procephalic lobe, the proctodeal primordium (which forms the hindgut), and the anterior and posterior midgut primordia (data not shown). Only labeling of the latter decays during the remainder of embryogenesis.

Completion of germ-band extension By the time epidermal segmentation becomes visible, three layers of accumulated protein can be seen that correspond to the ectoderm, neuroblasts, and mesoderm (Fig. 7F). The mesoderm appears to contain the highest levels of the protein at this time, perhaps corresponding to a wave of mitotic activity in these cells (see discussion of Notch expression in dividing cells, below). However, it is possible that some of the Notch protein in this region is the result of expression on neuroblast progeny. Notch expression in the stomodeal opening and possibly the salivary gland duct primordium is visible (Fig. 7F). At this point in development, neuroblasts have undergone division to produce ganglion mother cells (GMC), which in turn have produced neurons. It was not possible to distinguish by staining with the antibody, the latter two types of cells in embryos, but these neuroblast progeny are labeled in larval and pupal ventral ganglia (see below), indicating that comparable expression may occur in such cells during embryogenesis. As germ-band retraction commences, labeling of the salivary gland duct becomes clear (data not shown). Also, expression is seen in the invaginations in the pharynx forming the stomatogastric nervous system (data not shown).

Notch accumulates on longitudinal and commissural connectives of the newly condensed central nervous system After germ-band shortening, there is a gradual decay in the level of Notch protein in the ectoderm and mesoderm. However, Notch protein is abundant in the central nervous system (CNS) (Fig. 7G) and the peripheral nervous system (PNS) (data not shown). Within the CNS, strong labeling is present in the brain, the longitudinal and commissural processes, and some individual cells of the ventral nerve cord. The series of labeled cells lying along the midline probably correspond to the midline neuroblasts. Note that other mesodermal and ectodermal cells at this time do not express Notch (Figs. 71 and $8 \mathrm{~B}-\mathrm{D} \mid$. Other cells stained by the antibody occur laterally on the ventral surface of the ventral cord, and are probably also neuroblasts.

Final stages of embryogenesis By about stage 15, Notch is expressed most notably in the brain, ventral cord, foregut (especially in the area of the pharynx), the hindgut, Malpighian tubules, anterior and posterior spiracles (the labeling of the latter might be the result of the presence of the spiracular sensory organ, cf., Seeger et al. 1988) and salivary gland duct (Fig. 7H-J). Late in em- 
bryogenesis most of the staining by the antibody fades. The decay in staining intensity in the ectoderm, the mesoderm, and around the pharynx, allows Notch expression in the gonads, in some sensory organs of the head (Fig. 7J), and particularly, in the scolopale cells of the stretch receptors (Fig. 8A), to be seen.

Visualization of Notch protein in isolated larval and pupal CNS Notch expression in whole mounts of brains from first-, second-, and third-instar larvae, and early pupae were examined also. It was shown in Figure $8 \mathrm{D}$ that large cells, probably neuroblasts, lying on the ventral surface of the embryonic ventral ganglia produce high levels of Notch protein. By the end of embryogenesis, these cells express the highest levels of Notch protein detected in the CNS. These may correspond to the cells, as suggested by Vassin et al. (1987), which persist to form the imaginal nervous system. Evidence for this is seen in Figure $8 \mathrm{E}-\mathrm{G}$ where Notch antibody has been used to stain the CNS and brains of staged larvae. Little or no Notch expression is detected in early to midstage first-instar larvae (data not shown). In late first instar, a set of cells along the midline of the ventral ganglion begin to express Notch. These probably correspond to the embryonic midline neuroblasts. During the second instar, numerous labeled cells are seen in the thoracic ganglion, and then during early third instar, transient expression of Notch is detected in cells in the lateral abdominal ganglion. These cells occur in the same position as the lateral neuroblasts described in the embryo. Together with the midline cells the pattern in the abdominal ganglion is similar to that of the late embryonic CNS (cf. Fig. 8D to 8E). In addition, the transient expression of Notch in the lateral abdominal neuroblasts corresponds well with the peak of mitotic activity of these cells at this time (Truman and Bate 1988; also see below). Finally, in all of the larval stages, large cells, probably neuroblasts, are labeled in the optic lobes.

Figure $8, F$ and $G$, shows ventral and dorsal views of the brain and ventral ganglion of third-instar larvae. In third-instar larval (and pupal; data not shown/ ventral ganglion, pyramid-shaped clusters of cells that might correspond to neuroblasts, GMCs, and neurons with projecting axons are seen (Fig. $8 \mathrm{H}-\mathrm{J}$ ). In this family of cells, there is particularly intense staining by the Notch antibody between the larger and smaller cells (Fig. 8I,J). In addition to the labeling described above, Notch is expressed abundantly in the brain, particularly the optic lobes. The pattern of Notch expression in the larval ventral ganglion and optic lobes is remarkably similar to that seen by pulse-labeling this stage with bromodeoxyuridine (BrdU) (Truman and Bate 1988), suggesting that many cells expressing Notch at this time are dividing actively (Fig. 8F). None of the cells on the dorsal surface of the third-instar larval ventral ganglion (i.e., those that are mature), is labeled by the Notch antibody (Fig. 8G).

Later, in pupae, as formation of the imaginal nervous system continues, Notch is found on nondividing cells. Labeling of fascicles on the dorsal surface of the thoracic ganglion occurs in a segmented manner (data not shown). Within the brains of both larvae and pupae there are clusters of cells from which processes lead. Some of these cells are likely to be neurons with their projecting axons. Each cluster probably corresponds to progeny cells derived serially from a single neuroblast. Notch is expressed abundantly on the surface of the neuroblast in contact with what is probably a daughter cell [Fig. 8I,J\}. The distribution of Notch protein on the neuroblast progeny is highest on the projecting axons and on points of contact between neighboring cell bodies (Fig. $8 \mathrm{H}-\mathrm{J})$.

Figure 7. Distribution of the Notch protein during embryogenesis. Embryonic stages are based on Campos-Ortega and Hartenstein (1985). Where appropriate, anterior is left and dorsal is up. A midsagittal plane of focus is shown unless noted. Whole mounts of embryos $(A-I)$ were stained with anti-Notch (NT) antisera (see Materials and methods). $(A)$ The embryo at the top is Notch-deficient $\left[D f(1) N^{66 i 25}\right.$, see Fig. 1, legend], whereas the embryo at the bottom is wild type. The wild-type embryo is overstained to indicate complete absence of reactivity in Notch- embryo at same stage. $(B)$ Notch expression during blastoderm formation. The middle embryo is stage 3 (prior to inward growth of cell membranes), showing diffuse staining throughout its cytoplasm. The stage- 4 embryo to its left shows Notch accumulation on inwardly growing cell membranes. The stage- 5 embryo at the extreme right displays even greater Notch labeling, which at higher magnification (data not shown) is on cell membranes as blastoderm formation nears completion. Pole buds (stage 3) and pole cells (stages 4 and 5 ) (arrowheads) are not labeled by the Notch antibody. (C) A stage- 6 gastrulating embryo, superficial ventro-lateral plane of focus. Anterior to posterior 'bands' of Notch accumulation are visible in presumptive ventral neurogenic ectoderm flanking the ventral furrow (vf). (D) A stage- 8 germ band extending embryo. Notch accumulation is seen between the ectoderm (e) and mesoderm $(\mathrm{m})$. (E) Close-up of stage-9 embryo. Wave 1 of neuroblast segregation is occurring $($ CamposOrtega and Hartenstein 1985). Notch accumulation is found in three distinct cell layers: the palisade, columnar epithelial ectoderm (e), the large round neuroblasts (nb), and the cuboidal mesoderm $(\mathrm{m})$. Notch expression is polarized on the basal and lateral surfaces of the neuroblasts. $(F)$ Full germ band extended, stage-11 embryo is shown. Notch continues to be expressed in the three layers mentioned in $E$. Epithelial ectoderm cells (e) have now flattened. Highest mesodermal Notch expression occurs at this stage of development. Notch expression also can be detected in stomodeal opening (st) in area of the stomatogastric nervous system primordium. Additionally, salivary gland primordium ( $\mathrm{sg}$ ) labels with the antibody. $(G)$ A stage-13, germ-band retracted embryo. Antibody reacts with ventral cord (vc), commissures (co), anterior and posterior midgut primordia (am and pm, respectively), and hindgut (hg). ( $H$ ) A stage-17 embryo. Staining is primarily on ectodermal derivatives, particularly brain (br), ventral cord (vc), commissures (co), tracheae $(\mathrm{tr})$, and the posterior spiracle (ps). Note reduced overall labeling as compared to $G$. (I) Ventral view of stage-16 embryo. Note labeling of ventral cord (vc), midline neuroblasts (nb), commissures (co), and longitudinals (1). (J) Dorsal view of a stage-17 embryo. Notch accumulates in brain (br); label is especially apparent on supraoesophageal commissures (sec) and other nerve processes. Antennomaxillary complex (amc), anterior spiracle primordium (asp), posterior spiracle (ps), peripheral nervous system (pns), and gonads (go) react with the antibody. 

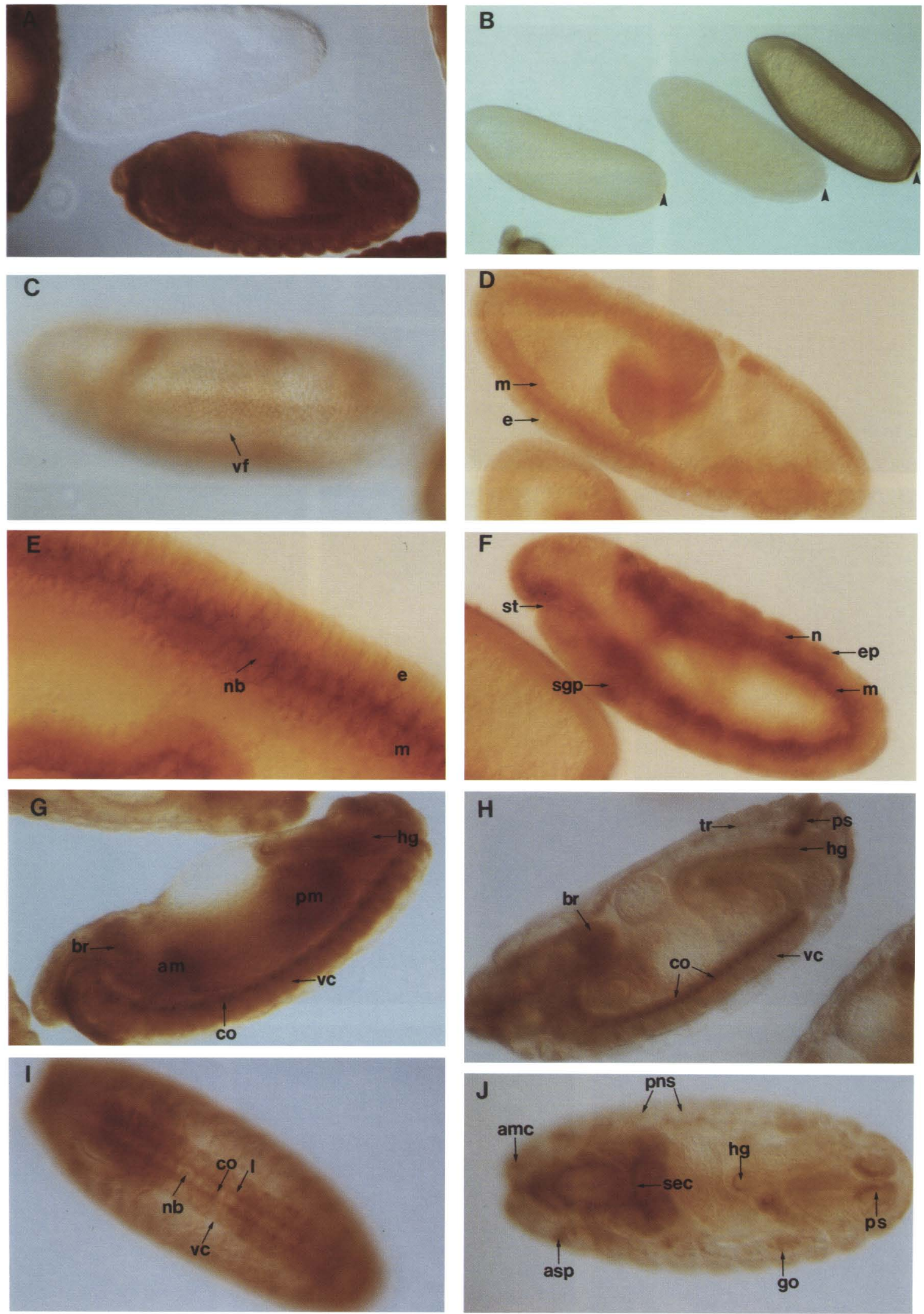

Figure 7. (See facing page for legend.) 
Kidd et al.
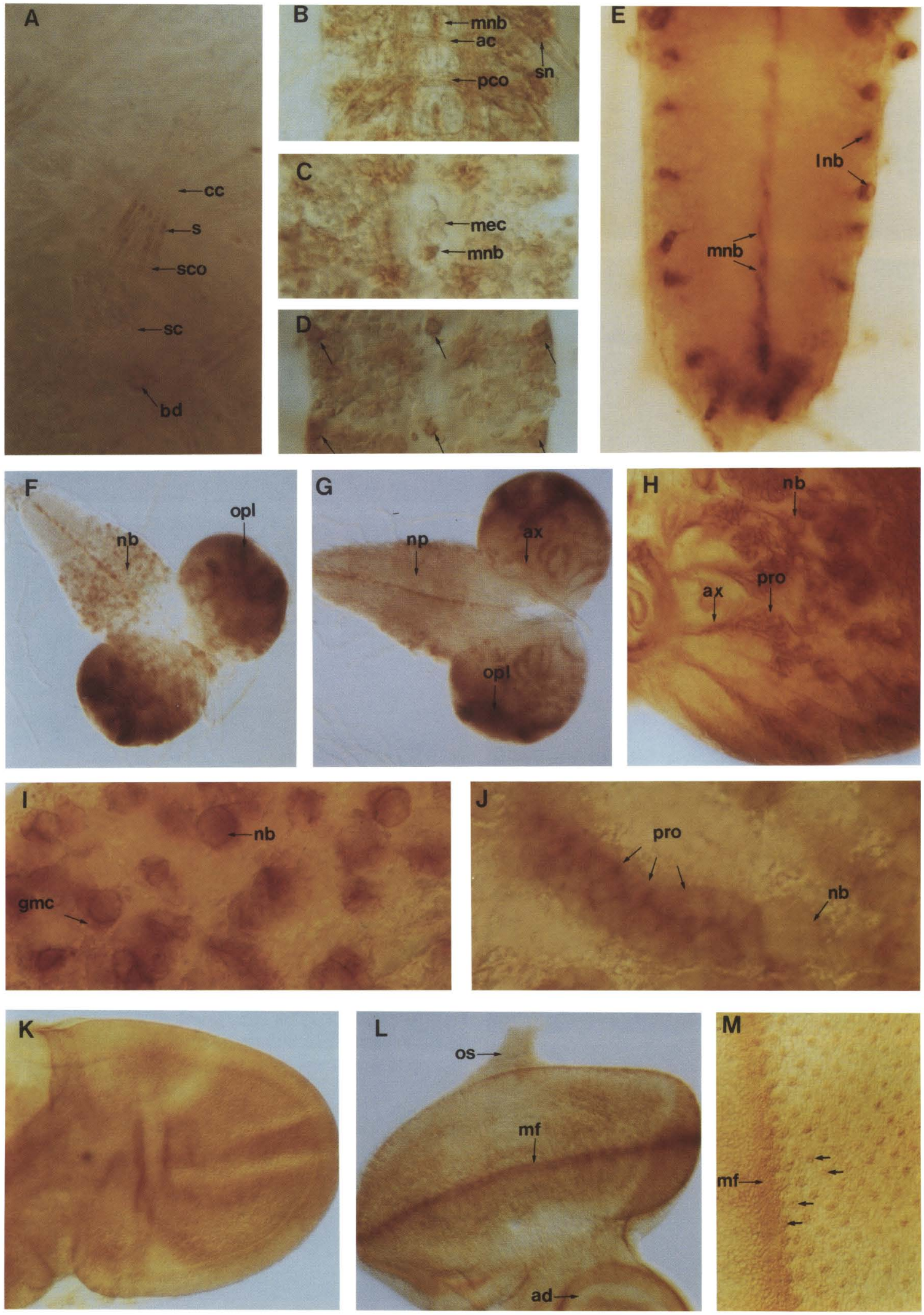

Figure 8. (See facing page for legend.) 
Notch is expressed in imaginal discs In third-instar larvae, the leg, wing, and haltere discs react relatively uniformly with the anti-Notch antibody /data not shown). At pupation the labeling begins to fade. In the wing disc, the pattern of residual expression looks similar to the venation pattern of the adult wing (Fig. $8 \mathrm{~K}$ ). The larval eye-antennae disc expresses Notch also. In the eye disc, labeling is seen along the morphogenetic furrow (Fig. 8L). Under high magnification there are, at regularly spaced intervals, clusters of labeled cells (Fig. $8 \mathrm{M}$ ) whose destiny will be to form a single ommatidium. Thus, the developing R2, R3, R4, R5, and R8 cells (Tomlinson and Ready 1987) appear to express Notch intensely on the apical surface within the morphogenetic furrow, and as they leave it. As shown in Figure 8M this results in the formation of a rectilinear array of Notchexpressing, developing ommatidia posterior to the furrow.

\section{Discussion}

Earlier work with temperature-sensitive mutations has shown that Notch protein is required for viability during most of the Drosophila life cycle (Shellenbarger and Mohler 1975). Lack of Notch protein during embryonic neurogenesis results in the transformation of presumptive epidermoblasts into neuroblasts. This condition leads to hypertrophy of the CNS and PNS, with a concomitant absence of epidermal derivatives of the neurogenic region. Mesodermal and endodermal stem cells are thought to be unaffected by the lack of Notch; the structural abnormalities that are detected in derivative tissues are attributed to changes caused by the neural and epidermal defects (Poulson 1937; Wright 1970; Lehmann et al. 1983). Although all deficits that result from lack of Notch protein later in development have not been well-characterized, various mutant alleles of Notch result in defects in the eyes, wings, legs, and bristles of the adult, and at least some of these mutant phenotypes result from assumption of inappropriate cell fates (Lindsley and Grell 1968; Lindsley and Zimm 1985; Cagan and Ready 1989). For example, loss of Notch in the differentiating eye can switch the developmental fates of cone cells, photoreceptors, bristles, and pigment cells (Cagan and Ready 1989).

The origins of neural hypertrophy in Notch mutants have been explored through mosaic analysis and cell transplantation experiments. These suggest that during neurogenesis, Notch protein acts close to the site of its synthesis. In fact, to form epidermis, a cell must synthesize its own Notch protein or, if lacking the protein, be surrounded by Notch-expressing cells (Portin 1980; Hoppe and Greenspan 1986; Technau and Campos-Ortega 1987).

In this paper it has been shown that antibodies against Notch protein detect a $350-\mathrm{kD}$ protein which, as expected, is expressed throughout development. The biochemical and immunocytochemical studies of the protein indicate that, in the majority of cells in which it is expressed, it is a long-lived, unprocessed, integral membrane protein with EGF-like repeats exposed on the cell surface. These findings fit well with expectations derived from the earlier DNA sequencing, transplantation, and genetic analyses.

The Notch protein in its native form appears to be a disulfide-bonded dimer. The cysteines of the extracellular EGF-like repeats of Notch, as in other EGF-related proteins (cf., Cooke et al. 1987), most likely form intramolecular disulfide bonds. The intermolecular bonds of the dimer could involve any of three remaining cysteines in the extracellular domain, at amino acid posi-

Figure 8. Notch protein distribution during late embryogenesis and larval stages. $A-M$ were stained with NT antibody /see Materials and methods). (A) Notch expression in the peripheral nervous system: the pentascolopidial chordotonal organ, and black dot from a stage-16 embryo. Notch accumulates primarily in the intracellular scolopales, at extracellular dendritic sheaths (s) of scolopale cells (sco) and at black dots (bd) (Hartenstein 1988). (cc) Cap cells; (sc) scolopale neurons. (B-D) Embryo fillets showing dissected ventral nerve cords (abdominal segments) reacting with antibody. Anterior is up and posterior is down. $B$ and $C$ are a stage-15 embryo at different planes of focus. Note Notch staining in longitudinals, anterior and posterior commissures (ac and pco, respectively), segmental nerve (sn), and median neuroblasts (mnb). Axons forming anterior and posterior commissures appear to label in varying intensities. In $C$, antibody labels median neuroblasts, but no other mesectoderm cells (mec) along the midline. (D) An older embryo in a ventral plane of focus. Notch distinctly accumulates on the midline neuroblast and one, perhaps two lateral neuroblasts on each side per segment as indicated by the arrows. $(E)$ Abdominal segments of ventral ganglia of early third-instar larva. Notch accumulates in the midline neuroblasts $(\mathrm{mnb})$ and lateral neuroblasts $(\operatorname{lnb})$. The pattern is reminiscent of that seen in late embryogenesis (see $D)$. $(F$ and $G$ ) Third-instar brain hemispheres and anterior ganglia. Posterior is left and anterior is right. (F) Antibody reaction on the ventral surface is shown. Notch expression occurs along midline, in thoracic neuroblasts (nb), and in neuroblasts of brain and optic lobe region (opl). $(G)$ Dorsal surface of a comparably staged third-instar brain and ganglia is shown. Antibody stains the optic lobe region (opl), axons (ax) in the brain, and midline of ganglia. No staining is seen in neuropile (np) of the ganglia or in lateral abdominal neuroblasts shown in $E$. $(H)$ Close up of third-instar brain hemisphere (dorsal surface depicted, optic lobe region at left). Neuroblasts show especially strong reactivity (nb), their progeny (pro), and axons (ax) are stained also. (I) Higher magnification of neuroblasts of the third-instar thoracic ganglia. Notch accumulates at cell borders, especially between neuroblasts (nb) and progeny (gmc, ganglion mother cell). Similar staining patterns are seen in pupal stages (data not shown). (J) Higher magnification of neuroblast and progeny from brain hemisphere of third-instar larva. Notch is localized at cell borders between offspring of neuroblasts (nb). In lower plane of focus (data not shown), projecting axons from this cluster label with the Notch antibody. (pro) Neuroblast progeny. (K) Wing disc from early pupa. Staining pattern is reminiscent of wing vein configuration seen in adults. $(L$ and $M)$ Eye disc from third-instar larva. Notch accumulates dramatically in morphogenetic furrow $(\mathrm{mf})$. Higher magnification and peripodial membrane removal ( $M)$ show Notch expression not only in the morphogenetic furrow ( $\mathrm{mf}$ ) but also in clusters of photoreceptors as they emerge from the furrow (arrows). (os) Optic stalk; (ad) antennal disc. 
tions 18, 1693, and 1696 (Kidd et al. 1986). Notch has two potential initiation codons before the signal sequence, with the cysteine 18 residue between the two (Kidd et al. 1986). Therefore, this cysteine either is not translated or, if translated, is removed with the signal sequence. The remaining two cysteines are in an analogous position to two cysteine residues which form intermolecular disulfide bonds in the homodimeric transferrin receptor (Jing and Trowbridge 1987). Thus, the corresponding amino acids in Notch may perform a similar function.

Previous studies suggest that mutations in some EGFlike elements affect interactions between individual Notch polypeptide chains (Kelley et al. 1987). Seven dominant Abruptex alleles of Notch are associated with amino acid substitutions in a cluster of six adjacent, EGF-like repeats (Kelley et al. 1987), and two complementation groups are formed by negative allelic interactions: Heterozygous combinations of Abruptex alleles from different subgroups produce lethality, whereas homozygotes and heterozygotes produced within a group are fully viable (Foster 1975; Portin 1975). None of the mutations examined affect dimer formation even in combinations that give negative complementation (S. Kidd, unpubl.). This suggests that these mutations affect the activity of the dimeric protein rather than its formation.

It is shown in this paper that the cytoplasmic domain of Notch is phosphorylated on serine, probably at multiple sites. There also appear to be variations in the level of phosphorylation found on the proteins isolated from developing embryos. Examination of the DNA-derived protein sequence of Notch reveals the presence of consensus sequences for phosphorylation on serine by both cAMP-dependent kinase and protein kinase $\mathrm{C}$ /Cohen 1985; Turner et al. 1985). However, the locations of phosphorylated residues have not been mapped precisely within the cytoplasmic domain. This phosphorylation, nevertheless, may represent an opportunity for regulation of Notch without new synthesis or protein turnover.

Immunocytochemistry has revealed aspects of Notch expression that may give insight into how the protein functions. During embryonic neurogenesis cells within the ventral neurogenic ectoderm use positional cues to choose between neural and epidermal fates. Notch is expressed uniformly in the ventral neurogenic region, suggesting that presumptive neuroblasts and epidermoblasts are both labeled with the Notch protein. Neuroblasts and epidermoblasts eventually show differential expression of Notch, with neuroblasts producing higher levels of the protein, but only after the cell types have segregated. As organization of the embryonic and larval nervous systems proceeds, Notch continues to be expressed on neuroblasts and progeny of varying ages. For many of these cells, Notch expression persists on points of cell contact, possibly through terminal differentiation. Even fasciculating neural projections are labeled abundantly with the protein. During the third larval instar, Notch is expressed again on differentiating ecto- derm. Notch is expressed within the morphogenetic furrow of the developing eye. Cell differentiation in the eye is determined by position rather than lineage, and instructive cell interactions, presumably, are initiated in the morphogenetic furrow (Tomlinson and Ready 1987). The protein appears to be associated uniformly with cells as they aggregate to form precursors of the ommatidia. As developing ommatidia detach from the furrow, Notch synthesis continues, resulting in an array of labeled ommatidia of different ages. The pattern of Notch expression corresponds well with that expected for a molecule that is necessary for position-dependent development, and as in embryonic neurogenesis, supports a role for the protein both before and after differentiation. However, the uniformity of Notch expression among cells that will assume different developmental potentials suggests that Notch protein alone may not be sufficient to elaborate cell fates.

Initial models for Notch protein function supposed that the protein would be found on a limited number of cells and signal cell fate in neurogenic tissue through intercellular interaction with a receptor (for review, see Wright 1970; Campos-Ortega 1985, 1988). Some support for these models has been taken from homologies found between Notch protein and growth factors (Wharton et al. 1985; Kidd et al. 1986). Certainly from the immunocytochemical studies, it is possible that Notch provides an essential signal for both commitment and maintenance of differentiation, but the patterns of Notch expression point as easily to a more passive role. Tandemly repeated EGF-like sequences have been found in several proteins that, like Notch, are unprocessed; and currently the largest body of examples involves the many EGF-homologous adhesion molecules (cf., Lawler and Hynes 1986; Sasaki et al. 1987; Jones et al. 1988; Montell and Goodman 1988; Bevilacqua et al. 1989; Mann et al. 1989; Siegelman et al. 1989). These proteins provide a material for long-term cell-to-cell associations in both developing and differentiated tissue. Moreover, a specific role in adhesion has been established for the EGFlike sequences in some of these molecules (Graf et al. 1987a,b; Iwamoto et al. 1987).

Hoppe and Greenspan (1986) have proposed that during neurogenesis, rather than behaving as a specific developmental signal, Notch functions by providing adhesion among presumptive epidermal cells. Although the distribution of the protein observed in this paper might better support involvement in neuroblast-toneuroblast or neuroblast-to-mesoderm interactions, the proposed alternative role in cell adhesion warrants further consideration. For example, Notch is expressed at the ectoderm-mesoderm border prior to neurogenesis and becomes largely restricted to the basal and lateral surfaces of neuroblasts as delamination begins. Lower levels of uniform Notch expression evolve on epidermoblasts. In this arrangement, if it were acting as an adhesion molecule, Notch protein might allow new, selective interactions of the migrating neuroblasts and underlying mesoderm, or an extracellular matrix secreted by the mesoderm or ectoderm. Possibly, in Notch null 
mutants, a loss of fixed-cell contacts and stable stratification of epidermal, neural, and mesodermal precursors, allows neurogenic interactions among cells to be so sufficiently unrestrained as to overpopulate the growing nervous system. Inappropriate patterns of differentiation in the eyes of Notch mutants (Cagan and Ready 1989) might have a similar basis. In any event, at one extreme it is possible to imagine how Notch might produce its developmental effects only by virtue of a requirement for adhesion. It may be important that adhesion and developmental signaling sometimes are linked to the same protein. For example, full-length molecules of laminin not only promote adhesion, but also behave as mitogens in cell culture (Panayotou et al. 1989). Mitogenic activity and adhesion are, in this case, dependent on different parts of the molecule, although both may involve regions of laminin homologous to EGF. A possible role for Notch proteins in cell interactions of this sort might be addressed by cell aggregation and antibody-blocking experiments.

In addition to the patterns of stable protein expression seen in developing and terminally differentiated tissue, an intriguing correspondence of Notch protein synthesis and mitotic activity is found during larval development. Throughout the nervous system, highest levels of Notch protein synthesis occur on neuroblasts. The pattern of Notch labeling is very similar to that produced by pulselabeling with BrdU (Truman and Bate 1988). Transient Notch expression is seen on certain abdominal neuroblasts, and the time of synthesis corresponds to time of BrdU incorporation by these cells (Truman and Bate 1988). This suggests that neuroblasts tend to express highest levels of Notch when they are dividing. Similarly, Notch protein appears to be produced at its highest levels in the mesoderm during periods of cell division. This correspondence is not absolute; for example, the midline neuroblasts of the first-larval instar ganglion express Notch before cell division, and no increase in Notch expression is seen in the waves of cell division, which occur posterior and anterior to the morphogenetic furrow of the eye disc. Although the function of Notch protein synthesis in subsets of dividing cells is unknown, it may be essential to maintain a developmental signal or appropriate cell interactions from the time of cell birth. In this regard, it may be important that coding-sequence homologies have been discovered recently by comparing Notch and certain genes central to yeast cell-cycle control (Breeden and Nasmyth 1987).

Another surprising pattern of Notch protein synthesis evolves during embryogenesis. Notch is expressed in mesodermal cells throughout much of embryogenesis, and is detected first as neuroblasts begin to segregate from the neurogenic ectoderm. Prior genetic and developmental studies have not pointed to a function for Notch in mesoderm organization. Although Notch may play an undetermined role in development of this germ layer, it is also conceivable that loss of protein synthesis in the mesoderm contributes to the aberrant neural phenotypes produced by Notch null mutants. Perhaps close association of ectodermal cells and mesoderm is as cen- tral to neurogenesis in insects as it is in vertebrates /Spemann 1938). Some insight into the role of mesodermal Notch expression may come from examination of mutations affecting mesoderm development, or through analysis of neural development in genetic mosaics showing defects in Notch expression that are restricted to mesoderm.

\section{Materials and methods}

\section{Preparation of antibodies}

Restriction fragments from both cDNA and genomic DNA clones (both Oregon R and Canton S strains) were inserted into the appropriate pATH vectors (Dieckmann and Tzagoloff 1985). (For locations of fragments see Fig. 1a.) In the following description, the nucleotide numbers are preceded by ' $\mathrm{nt}$ ' and correspond to those of the mRNA (Kidd et al. 1986); the amino acid residue numbers follow, and are preceded by 'aa.' B2.4 is a HindIII-BamHI fragment (nt971-3403, aa59-869). The HindIII site was generated by $B a 131$ digestion from the $H p a I$ site at nt777 and the addition of HindIII linkers. NT results from KpnI digestion of B2.4 at nt1213 giving aa59-138. BP is a BamHIPstI fragment (nt3403-4531, aa869-1246). BPC is from partial ClaI digestion of BP at nt4463 (aa1223). NR is an NruI fragment (nt6164-7027, aal790-2077). DPA is a BamHI-HindIII fragment (nt5192-5994, aal466-1731). The HindIII site was produced by Bal31 digestion from the NruI site at nt6164 and ligation of HindIII linkers. DPB is a PstI-BamHI fragment (nt4531-5192, aa1246-1466). DPB was not used to raise antibody, but was used in affinity purification (see below).

These pATH fusions were transformed into Escherichia coli $\mathrm{HB} 101$ and insoluble fusion proteins were prepared as described by Spindler et al. (1984). With the exception of the NT antibody (see below), the fusion proteins were further purified by preparative SDS-polyacrylamide gel electrophoresis (SDS-PAGE). The proteins were located by staining the gel with $4 \mathrm{M}$ sodium acetate (Higgins and Dahmus 1979) and the portion of the gel that contained the protein was excised and minced. The protein then was eluted by diffusion into phosphate buffered saline (PBS). The eluted protein $(300 \mu \mathrm{g})$ was mixed with Freund's complete adjuvant and injected subcutaneously into two, 2month-old female New Zealand White rabbits. These rabbits were boosted every 3-4 weeks with $50 \mu \mathrm{g}$ of protein in Freund's incomplete adjuvant with serum being collected $2-3$ weeks after the boost. Antibodies directed against the external domain of Notch had considerable variation in the titer when determined by the ability to immunoprecipitate Notch protein. Antibodies against the Notch portion of the fusion protein were affinity-purified by passage over an Affigel 10 column linked to an unpurified preparation of an unrelated trpE fusion protein, and then positively selected on a column of the appropriate fusion protein. This was washed with 100 volumes of $1 \mathrm{M} \mathrm{NaCl}$ in PBS and then with 100 volumes of $1 \%$ NP- 40 in PBS. The antibody then was eluted with either $4 \mathrm{M}$ guanidine $\mathrm{HCl}$ in $10 \mathrm{~mm}$ HEPES (pH 8), or with $50 \%$ ethylene glycol in $0.1 \mathrm{M}$ glycine $\mathrm{HCl}(\mathrm{pH} 2.5)$, in which case it was neutralized with an equal volume of $1 \mathrm{M}$ HEPES (pH 8). The antibodies then were dialyzed against PBS and stored in PBS containing 50\% glycerol.

Because none of the antibodies prepared as described above worked on whole mounts of Drosophila embryos, a different procedure was used to generate the NT antibody. Initally rabbits were immunized and boosted once with B2.4. Subsequent boosts and affinity purification of antibodies used in this paper were with NT. Both proteins were purified as follows: 
The insoluble fusion proteins were dissolved in $6 \mathrm{M}$ guanidine $\mathrm{HCl}, 50 \mathrm{~mm}$ HEPES (pH 8.0), $1 \mathrm{~mm}$ oxidized glutathione, and then refolded by sequential dialysis against $4,3,2.5,2,1.5$, and $1 \mathrm{M}$ guanidine $\mathrm{HCl}$ plus $10 \mathrm{~mm}$ reduced and $1 \mathrm{~mm}$ oxidized glutathione (Ahmed et al. 1975) in $50 \mathrm{~mm}$ HEPES (pH 8.0). This was followed by several dialysis changes against PBS. Insoluble material was removed by centrifugation, and protein in the soluble fraction was concentrated in a Centriprep 30 . This protein then was used to raise antibodies as described above. Subsequently, these were affinity-purified on a NT trpE fusion protein column. Antibodies against trpE and those that may cross-react with other EGF-like sequences were removed by passage over a column that contained crude preparations of two fusion proteins (BPC and DPB), which contain EGF-like sequences from Notch protein but do not overlap NT. Finally, the antibody was passed over a column of first-instar larval proteins to remove any residual cross-reactivity.

\section{Gel electrophoresis and immmunoblotting}

SDS-PAGE was carried out by the procedure of Laemmli (1970). The loading buffer, unless noted, contained a final concentration of either $0.1 \mathrm{M}$ DTT or $10 \% \beta$-mercaptoethanol. Protein size markers were either Amersham Rainbow markers or high-molecular-weight markers from Pharmacia. These include thyroglobulin, which has a molecular weight of $\sim 340 \mathrm{kD}$ when reduced and was detected by Coomassie Blue staining. Radiolabeled proteins were detected by either autoradiography or fluorography using either Amplify (Amersham) or Enhance (NEN). Proteins were blotted onto $0.1-\mu \mathrm{m}$ pore nitrocellulose, either in a buffer of $10 \mathrm{~mm}$ MOPS ( $\mathrm{pH} 7.5$ ), $4 \mathrm{~mm}$ sodium acetate, $0.1 \%$ SDS, $20 \%$ ethanol at 25 volts overnight at $4^{\circ} \mathrm{C}$, or in Laemmli (1970) electrophoresis buffer containing $20 \%$ methanol in a Bio-Rad Mini Trans-Blot apparatus at 100 volts for $1 \mathrm{hr}$.

Detection of proteins bound to nitrocellulose was carried out at room temperature. The filter was incubated in blocking solution [10 mM Tris $\mathrm{HCl}$ (pH 8), $150 \mathrm{mM} \mathrm{NaCl}, 0.05 \%$ Tween 20 (TBST)] plus detergents $10.5 \%$ sodium deoxycholate, $0.2 \%$ NP-40, $0.02 \%$ SDS/ and 5\% Carnation nonfat dried milk for 30 min. This was followed by overnight incubation with the primary antibody in the same solution. The filter then was washed three times for $10 \mathrm{~min}$ each wash in TBST plus detergents, $1 \times 10 \mathrm{~min}$ in blocking solution, and then incubated for $2 \mathrm{hr}$ with alkaline phosphatase (Promega), or biotin-conjugated goat anti-rabbit antibody (Jackson) in blocking solution. In the latter case, the filter was washed again as described above for the first antibody, incubated for $1 \mathrm{hr}$ with alkaline phosphatase-conjugated streptavidin (Jackson) in blocking solution, and then washed three times for $10 \mathrm{~min}$ each wash in TBST plus detergents. At this point filters incubated with either secondary antibody were washed three times for $5 \mathrm{~min}$ each wash with TBST, and alkaline phosphatase activity was detected as described by the manufacturer (Promega). Use of a biotinylated second antibody increased the sensitivity but also resulted in the detection of a $120-\mathrm{kD}$ protein which is not the result of the first antibody. Detection of filter-bound glycoproteins by Con A was as described by Wilcox (1986).

\section{Preparation of Drosophila protein}

The following protease inhibitors were used during the isolation of Drosophila proteins: $20 \mu \mathrm{g} / \mathrm{ml}$ of pepstatin A, $20 \mu \mathrm{g} / \mathrm{ml}$ of leupeptin, $20 \mu \mathrm{g} / \mathrm{ml}$ of antipain, $20 \mu \mathrm{g} / \mathrm{ml}$ of soya bean trypsin inhibitor (SBTI), $200 \mathrm{kIU} / \mathrm{ml}$ of Trasylol (aprotinin), $0.44 \%$ benzamidine, and $2 \mathrm{mM}$ PMSF. Total proteins for the developmental profile (Fig. 1c) were prepared by homogenizing organisms in $10 \mathrm{~mm}$ HEPES (pH 7.4), 5\% SDS, 5 mM EGTA, and $5 \mathrm{mM}$ EDTA plus benzamidine, leupeptin, and PMSF (SDS lysis buffer). After boiling for $5 \mathrm{~min}$ the samples were cleared by centrifugation in a Beckman TLA 100.1 rotor at $180,000 \mathrm{~g}$ for 90 min, and analyzed by SDS-PAGE (Laemmli 1970). Total proteins for the analysis of disulfide bonds by immunoblotting (Fig. 6a) were extracted by homogenization of dechorionated embryos or pupae in PBS, $5 \mathrm{~mm}$ EDTA, $5 \mathrm{~mm}$ EGTA, $1 \%$ Triton $\mathrm{X}-100$, and $20 \mathrm{mM}$ iodoacetamide (IAA) plus protease inhibitors. After clarification at $37,000 \mathrm{rpm}$ in a Beckman type 40 rotor for $1 \mathrm{hr}$ at $4^{\circ} \mathrm{C}$, the supernatant was mixed with an equal volume of Laemmli (1970) loading buffer containing varying amounts of DTT, boiled for $5 \mathrm{~min}$, and analyzed by SDS-PAGE.

Drosophila embryonic cells were prepared by homogenization of dechorionated embryos on ice in PBS plus protease inhibitors, followed by filtration through several layers of 60 mesh Nitex. The cells were pelleted at $500 \mathrm{rpm}$ for $5 \mathrm{~min}$, washed once in PBS with inhibitors, and then resuspended in the same solution. The cells were lysed by the addition of Triton X-100 to a final concentration of $1 \%$. After $10 \mathrm{~min}$ on ice the lysates were clarified in a microfuge and the supernatant was mixed with an equal volume of $2 \times$ Laemmli gel loading buffer. Generally, from $20-30 \mu \mathrm{l}$ of packed cells were loaded per gel lane. In some experiments, proteins in the cleared lysate were immunoprecipitated as described below.

For metabolic labeling of Drosophila embryonic cells, dechorionated embryos were homogenized as above using either BSS (Wilcox 1986) or methionine- and cysteine-free Minimal Eagle's Medium (MEM). The cells were resuspended in either MEM, or cysteine- and methionine-free or phosphate-free M3 media containing $10 \%$ dialyzed, heat-inactivated fetal bovine serum. The cells were labeled at room temperature immediately or preincubated for $1 \mathrm{hr}$ prior to addition of ${ }^{35} \mathrm{~S}$-labeled amino acid(s) (Amersham or NEN), each at $200-500 \mu \mathrm{Ci} / \mathrm{ml}$, or ${ }^{32} \mathrm{PO}_{4}$ (Amersham; carrier free) at $0.5 \mu \mathrm{Ci} / \mathrm{ml}$. After labeling, the cells either were lysed immediately or were chased for varying periods of time in complete M3 media. Treatment of cells with tunicamycin $(40 \mu \mathrm{g} / \mathrm{ml})$ (Hubbard and Ivatt 1981) was for $3 \mathrm{hr}$ in M3 media and also during the radiolabeling of the cells as described above. At the end of the labeling or chase period the cells were pelleted and lysed in either SDS lysis buffer as above (Figs. $2 \mathrm{~b}$ and 3 ), or on ice in $50 \mathrm{mM}$ Tris- $\mathrm{HCl}$ (pH 7.6), $150 \mathrm{~mm} \mathrm{NaCl}, 10 \mathrm{~mm}$ EGTA, $20 \mathrm{~mm}$ EDTA, and $1 \%$ Triton X-100 plus protease inhibitors. When proteins were analyzed in the unreduced state (Fig. $6 \mathrm{~b}$ ), $10 \mathrm{~mm}$ IAA was added to this solution; for ${ }^{32} \mathrm{P}$-labeled proteins, this solution also contained $100 \mathrm{mM} \mathrm{NaF}, 10 \mathrm{~mm}$ pyrophosphate, and $0.2 \mathrm{~mm}$ $\mathrm{Na}_{3} \mathrm{VO}_{4}$. After $10 \mathrm{~min}$ on ice, the lysate was clarified by centrifugation for $15 \mathrm{~min}$ in a microfuge at $4^{\circ} \mathrm{C}$. Samples in SDS lysis buffer were adjusted to $0.375 \%$ SDS and $2 \%$ Triton X-100 and immunoprecipitated as described by Anderson and Blobel (1983). Those lysed with Triton X-100 were preincubated with protein A-Sepharose beads for $2 \mathrm{hr}$ at $4^{\circ} \mathrm{C}$. The samples were centrifuged to remove the beads and the supernatants were incubated with antibody and more protein A-Sepharose overnight at $4^{\circ} \mathrm{C}$. The beads then were washed at room temperature three times with RIPA detergents $\{1 \%$ Triton X-100, $1 \%$ deoxycholate, and $0.1 \%$ SDS) in $50 \mathrm{~mm}$ Tris- $\mathrm{HCl}(\mathrm{pH} 7.6), 150 \mathrm{~mm}$ $\mathrm{NaCl}, 5 \mathrm{~mm}$ EDTA, $5 \mathrm{~mm}$ EGTA; when ${ }^{32} \mathrm{P}$-labeled proteins were analyzed, this solution also contained $20 \mathrm{mM} \mathrm{NaF}, 10 \mathrm{mM}$ pyrophosphate, and $0.2 \mathrm{mM} \mathrm{Na}_{3} \mathrm{VO}_{4}$. The beads were washed twice with $10 \mathrm{~mm}$ Tris- $\mathrm{HCl}(\mathrm{pH} 7.6), 1 \mathrm{M} \mathrm{NaCl}, 0.5 \mathrm{~mm}$ EDTA, $0.5 \mathrm{~mm}$ EGTA, $0.1 \%$ Triton X-100, and once with RIPA in 10 
$\mathrm{mm}$ Tris- $\mathrm{HCl}(\mathrm{pH} 7.6), 10 \mathrm{~mm} \mathrm{NaCl}$, and $0.5 \mathrm{~mm}$ EDTA. Finally, the beads were resuspended in Laemmli loading buffer.

Trypsinization of $\mathrm{Kc}$ cells (or ${ }^{32} \mathrm{P}$-labeled embryonic cells) was carried out in M3 media minus serum with varying amounts of enzyme for varying times. The digestion was stopped by adding a twofold excess of SBTI. The cells were pelleted, lysed, and then immunoprecipitated. Subsequent analysis was by immunoblotting after SDS-PAGE.

For phosphoamino acid analysis, ${ }^{32} \mathrm{P}$-labeled Notch protein was excised from the gel following SDS-PAGE. The sample was rehydrated in $10 \%$ methanol and then lyophilized. The material was incubated in $50 \mu \mathrm{g} / \mathrm{ml}$ of trypsin in $50 \mathrm{~mm}$ $\left(\mathrm{NH}_{4}\right) \mathrm{HCO}_{3}$ for $24 \mathrm{hr}$. The digestion supernatant was lyophilized, boiled in $6 \mathrm{~N} \mathrm{HCl}$, and was subjected to several cycles of lyophilization and rehydration. After mixing with phosphoamino acid standards, samples were analyzed by electrophoresis on cellulose plates at 1000 volts for $1.5 \mathrm{hr}$ and visualized by ninhydrin staining and autoradiography.

\section{Immunocytochemistry}

Dechorinated embryos were fixed for $15 \mathrm{~min}$ in PBS, 4\% paraformaldehyde, and $20 \%$ DMSO saturated with an equal volume of heptane at room temperature. Vitelline membranes were removed as described by Mitchison and Sedat (1983). All subsequent steps are at room temperature. After rehydration the embryos were permeabilized in PBS with $0.5 \%$ Triton X-100 (PBST) for $30 \mathrm{~min}$, and endogenous peroxidase activity was removed by a 30 -min incubation in $0.3 \% \mathrm{H}_{2} \mathrm{O}_{2}$ in methanol. The embryos were blocked in PBST with filtered, heat-inactivated $10 \%$ goat serum (PBSTG) for $30 \mathrm{~min}$ and then incubated overnight at room temperature with antibody in PBSTG. Detection of the primary antibody was as follows using either regular or elite Vectastain kits (Vector Labs): The embryos were washed three times for 10 min each wash in PBST, blocked for $30 \mathrm{~min}$ in PBSTG, and incubated for $2 \mathrm{hr}$ with biotinylated goat antirabbit antibody in PBSTG. After three 10-min washes in PBST, the embryos were incubated for $1 \mathrm{hr}$ with preformed, avidinhorseradish peroxidase (HRP) complexes in PBST. Three 10min washes in PBST followed. Visualization of the HRP activity was as described by the manufacturer. The reaction was stopped by three washes in PBST with $0.04 \%$ azide. The embryos were dehydrated and mounted in Epon 812 (Poly/Bed 812, Polysciences, Inc.).

Dissection of embryonic nervous systems (fillets), larval and pupal brains, ventral ganglions and attached imaginal discs was in BSS (Wilcox 1986). Fillets were fixed in $2 \%$ paraformaldhyde in PBS for $20 \mathrm{~min}$, while larval and pupal CNSs were fixed in $4 \%$ paraformaldehyde in PBS for $15 \mathrm{~min}$. Eye discs were fixed in PLP (McLean and Nakane 1974). Subsequent steps were as described above except that the Triton X-100 concentration was reduced to $0.2 \%$ for fillets, and $0.1 \%$ Saponin was employed for eye discs. After stopping the HRP reaction, fillets and brains were dehydrated and cleared overnight in methyl salicylate. The fillets were mounted in cedarwood oil, whereas the brains were rehydrated, and after further dissection in PBST, were mounted in Aquamount (Lerner Labs). All tissues were viewed with Nomarski optics.

\section{Acknowledgments}

We thank Raphael Fernandez-Almonacid and Ora Rosen for supplying antibodies to the Drosophila insulin receptor and suggestions for its use, and for providing laboratory space. We thank Sally Kornbluth for phosphoaminoacid analyses. This work was supported by grants from the National Institutes of Health, and by the Howard Hughes Medical Institute.

\section{References}

Ahmed, A.K., S.W. Schaffer, and D.B. Wetlaufer. 1975. Nonenzymic reactivation of reduced bovine pancreatic ribonuclease by air oxidation and by glutathione oxidoreduction buffers. J. Biol. Chem. 250: 8477-8482.

Anderson, D.J. and G. Blobel. 1983. Immunoprecipitation of proteins from cell-free translation. Methods Enzymol. 96: $111-120$.

Bevilacqua, M.P., S. Stengelin, M.A. Gimbrone, and B. Seed. 1989. Endothelial leukocyte adhesion molecule 1: An inducible receptor for neutrophils related to complement regulatory proteins and lectins. Science 243: 1160-1165.

Breeden, L. and K. Nasmyth. 1987. Similarity between cellcycle genes of budding yeast and fission yeast and the Notch gene of Drosophila. Nature 329: 651-654.

Cagan, R.L. and D.F. Ready. 1989. Notch is required for successive cell decisions in the developing Drosophila retina. Genes Dev. 8: 1099-1112.

Campos-Ortega, J.A. 1985. Genetics of early neurogenesis in Drosophila melanogaster. Trends Neurosci. 8: 245-250.

. 1988. Cellular interactions during early neurogenesis of Drosophila melanogaster. Trends Neurosci. 11: 400-405.

Campos-Ortega, J.A. and V. Hartenstein. 1985. The embryonic development of Drosophila melanogaster. Springer-Verlag, New York.

Cohen, P. 1985. The role of protein phosphorylation in the hormonal control of enzyme activity. Eur. I. Biochem. 151: 439-448.

Cooke, R.M., A.J. Wilkinson, M. Baron, A. Pastore, M.J. Tapping, I.D. Campbell, H. Gregory, and B. Sheard. 1987. The solution structure of human epidermal growth factor. $\mathrm{Na}$ ture 327: 339-341.

Craymer, L. 1984. New mutants. Drosophila Inf. Serv. 60: 234.

Dieckmann, C.L. and A. Tzagoloff. 1985. Assembly of the mitochondrial membrane system. CBP6, a yeast nuclear gene necessary for synthesis of cytochrome b. I. Biol. Chem. 260: $1513-1520$.

Doe, C.Q. and C.S. Goodman. 1985a. Early events in insect neurogenesis. I. Development and segmental differences in the pattern of neuronal precursor cells. Dev. Biol. 111: 193205.

- 1985b. Early events in insect neurogenesis. II. The role of cell interactions and cell lineage in the determination of neuronal precursor cells. Dev. Biol. 111: 206-219.

Doolittle, R.F., D.F. Feng, and M.S. Johnson. 1984. Computerbased characterization of epidermal growth factor precursor. Nature 307: 558-560.

Echalier, G. and A. Ohanessian. 1970. In vitro culture of Drosophila melanogaster embryonic cells. In vitro 6: 162-172.

Fernandez-Almonacid, R. and O.M. Rosen. 1987. Structure and ligand specificity of the Drosophila insulin receptor. Mol. Cell Biol. 7: 2718-2727.

Foster, G.G. 1975. Negative complementation at the Notch locus of Drosophila melanogaster. Genetics 81: 99-120.

Graf, J., Y. Iwamoto, M. Sasaki, G.R. Martin, H.K. Kleinman, F.A. Robey, and Y. Yamada. 1987a. Identification of an amino acid sequence in laminin mediating cell attachment, chemotaxis, and receptor binding. Cell 48: 989-996.

Graf, J., R.C. Ogle, F.A. Robey, M. Sasaki, G.R. Martin, Y. Yamada, and H. Kleinman. $1987 \mathrm{~b}$. A pentapeptide from the 
laminin B1 chain mediates cell adhesion and binds the 67,000 laminin receptor. Biochemistry 26: 6896-6900.

Gray, A., T.J. Dull, and A. Ullrich. 1983. Nucleotide sequence of epidermal growth factor cDNA predicts a 128,000 molecular weight protein precursor. Nature 303: $722-725$.

Hartenstein, V. 1988. Development of Drosophila larval sensory organs: Spatiotemporal pattern of sensory neurones, peripheral axonal pathways and sensilla differentiation. Development 102: 869-886.

Hartley, D.A., T. Xu, and S. Artavanis-Tsakonas. 1987. The embryonic expression of the Notch locus of Drosophila melanogaster and the implications of point mutations in the extracellular EGF-like domain of the predicted protein. EMBO I. 6: $3407-3417$.

Higgins, R.C. and M.E. Dahmus. 1979. Rapid visualization of protein bands in preparative SDS-polyacrylamide gels. Anal. Biochem. 93: 257-260.

Hoppe, P.E. and R.J. Greenspan. 1986. Local function of the Notch gene for embryonic ectodermal pathway choice in Drosophila. Cell 46: 773-783.

Hubbard, C.S. and R.J. Ivatt. 1981. Synthesis and processing of asparagine linked oligosaccharides. Annu. Rev. Biochem. 50: $555-583$.

Iwamoto, Y., F.A. Robey, J. Graf, M. Sasaki, H.K. Kleinman, Y. Yamada, and G.R. Martin. 1987. YIGSR, a synthetic laminin pentapeptide, inhibits experimental metastasis formation. Science 238: $1132-1134$.

Jing, S. and I.S. Trowbridge. 1987. Identification of the intermolecular disulfide bonds of the human transferrin receptor and its lipid-attachment site. EMBO 1. 6: 327-331.

Jones, F.S., M.P. Burgoon, S. Hoffman, K.L. Crossin, B.A. Cunningham, and G.M. Edelman. 1988. A cDNA clone for cytotactin contains sequences similar to epidermal growth factor-like repeats and segments of fibronectin and fibrinogen. Proc. Natl. Acad. Sci. 85: 2186-2190.

Kelley, M.R., S. Kidd, W.A. Deutsch, and M.W. Young. 1987. Mutations altering the structure of epidermal growth factorlike coding sequences at the Drosophila Notch locus. Cell 51: 539-548.

Kidd, S., T.J. Lockett, and M.W. Young. 1983. The Notch locus of Drosophila melanogaster. Cell 34: 421-433.

Kidd, S., M.R. Kelley, and M.W. Young. 1986. Sequence of the Notch locus of Drosophila: relationship of the encoded protein to mammalian clotting and growth factors. Mol. Cell. Biol. 6: 3094-3108.

Laemmli, U.K. 1970. Cleavage of structural proteins during the assembly of the head of bacteriophage T4. Nature 227: 680685.

Lawler, J. and R.O. Hynes. 1986. The structure of human thrombospondin, an adhesive glycoprotein with multiple calcium-binding sites and homologies with several different proteins. I. Cell Biol. 103: 1635-1648.

Lehmann, R., F. Jimenez, U. Dietrich, and J.A. Campos-Ortega. 1983. On the phenotype and development of mutants of early neurogenesis in Drosophila melanogaster. Wilhelm Roux's Arch. Dev. Biol. 192: 62-74.

Lindsley, D.L. and E.H. Grell. 1968. Genetic variations of Drosophila melanogaster. Carnegie Inst. Wash. Publ. 627.

Lindsley, D.L. and G. Zimm. 1985. The genome of Drosophila melanogaster. Part 1: genes A-K. Drosophila Inf. Serv. 62.

Mann, K., R. Deutzmann, M. Aumailley, R. Timpl, L. Raimondi, Y. Yamada, T. Pan, D. Conway, and M. Chu. 1989. Amino acid sequence of mouse nidogen, a multidomain basement membrane protein with binding activity for laminin, collagen IV and cells. EMBO I. 8: 65-72.

McLean, I. and P. Nakane. 1974. Periodate-lysine-paraformal- dehyde fixative, a new fixative for immunoelectron microscopy. J. Histochem. Cytochem. 22: 1077-1082.

Mitchison, T. and J. Sedat. 1983. Localization of antibody determinants to whole Drosophila embryos. Dev. Biol. 99: $261-264$.

Montell, D.J. and C.S. Goodman. 1988. Drosophila substrate adhesion molecule: Sequence of laminin Bl chain reveals domains of homology with mouse. Cell 53: 463-473.

Panayotou, G., P. End, M. Aumailley, R. Timpl, and J. Engel. 1989. Domains of laminin with growth-factor activity. Cell 56: $93-101$.

Pognonec, P., K.E. Boulukos, J.C. Gesquiere, D. Stehelin, and J. Ghysdael. 1988. Mitogenic stimulation of thymocytes results in the calcium-dependent phosphorylation of c-ets-1 proteins. EMBO I. 7: 977-983.

Portin, P. 1975. Allelic negative complementation at the Abruptex locus of Drosophila melanogaster. Genetics 81: $121-133$.

- 1980. On the cell lethality of Notch and Abruptex mutations of Drosophila melanogaster. Hereditas 92: 303-307.

Poulson, D.F. 1937. Chromosomal deficiencies and embryonic development of Drosophila melanogaster. Proc. Natl. Acad. Sci. 23: 133-137.

Russell, D.W., W.J. Schneider, T. Yamamoto, K.L. Luskey, M.S. Brown, and J.L. Goldstein. 1984. Domain map of the LDL receptor: Sequence homology with the epidermal growth factor precursor. Cell 37: 577-585.

Sasaki, M., S. Kato, K. Kohno, G.R. Martin, and Y. Yamada. 1987. Sequence of cDNA encoding the laminin Bl chain reveals a multidomain protein containing cysteine-rich repeats. Proc. Natl. Acad. Sci. 84: 935-939.

Scott, J., M. Urdea, M. Quiroga, R. Sanchez-Pescador, N. Fong, M. Selby, W. Rutter, and G.I. Bell. 1983. Structure of a mouse submaxillary messenger RNA encoding epidermal growth factor and seven related proteins. Science 221: 236240.

Seeger, M.A., L. Haffley, and T.C. Kaufman. 1988. Characterization of amalgam: A member of the immunoglobin superfamily from Drosophila. Cell 55: 589-600.

Shellenbarger, D.L. and J.D. Mohler. 1975. Temperature-sensitive mutations of the Notch locus in Drosophila melanogaster. Genetics 81: 143-162.

Siegelman, M.H., M. van de Rijn, and I.L. Weissman. 1989. Mouse lymph node homing receptor cDNA clone encodes a glycoprotein revealing tandem interaction domains. Science 243: 1165-1172.

Spemann, H. 1938. Embryonic development and induction. Yale University Press, New Haven, Connecticut.

Spindler, K.R., D.S.E. Rosser, and A.J. Berk. 1984. Analysis of adenovirus transforming proteins from early regions $1 A$ and $1 \mathrm{~B}$ with antisera to inducible fusion antigens produced in Escherichia coli. J. Virol. 49: 132-141.

Technau, G.M. 1987. A single cell approach to problems of cell lineage and commitment during embryogenesis of Drosophila melanogaster. Development 100: 1-12.

Technau, G.M. and J.A. Campos-Ortega. 1987. Cell autonomy of expression of neurogenic genes of Drosophila melanogaster. Proc. Natl. Acad. Sci. 84: 4500-4504.

Tomlinson, A. and D. Ready. 1987. Neuronal differentiation in the Drosophila ommatidium. Dev. Biol. 120: 366-376.

Truman, J.W. and M. Bate. 1988. Spatial and temporal patterns of neurogenesis in the central nervous system of Drosophila melanogaster. Dev. Biol. 125: 145-157.

Turner, R.S., B.E. Kemp, H. Su, and J.F. Kuo. 1985. Substrate specificity of phospholipid/ $\mathrm{Ca}^{2+}$-dependent protein kinase as probed with synthetic peptide fragments of the bovine 
myelin basic protein. J. Biol. Chem. 260: 11503-11507.

Vassin, H., K.A. Bremer, E. Knust, and J.A. Campos-Ortega. 1987. The neurogenic gene Delta of Drosophila melanogaster is expressed in neurogenic territories and encodes a putative transmembrane protein with EGF-like repeats. EMBO I. 6: 3431-3440.

Wharton, K.A., K.M. Johansen, T. Xu, and S. Artavanis-Tsakonas. 1985. Nucleotide sequence from the neurogenic locus Notch implies a gene product that shares homology with protein containing EGF-like repeats. Cell 43: 567-581.

Wilcox, M. 1986. Cell surface antigens. In Drosophila: A practical approach (ed. D.B. Roberts), pp. 243-274. IRL Press, Oxford.

Wright, T.R.F. 1970. The genetics of embryogenesis in Drosophila. Adv. Genet. 15: 261-395. 


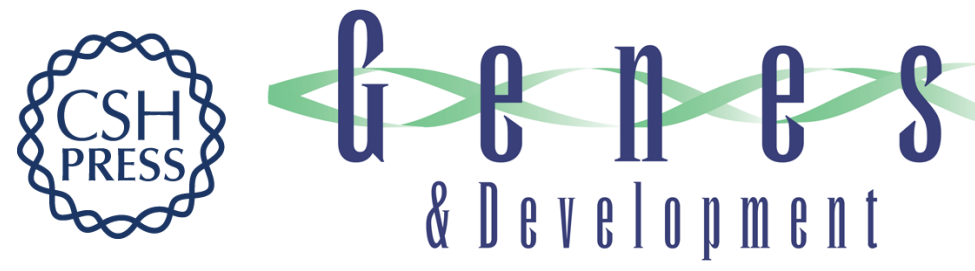

\section{Structure and distribution of the Notch protein in developing Drosophila.}

S Kidd, M K Baylies, G P Gasic, et al.

Genes Dev. 1989, 3:

Access the most recent version at doi:10.1101/gad.3.8.1113

References This article cites 58 articles, 20 of which can be accessed free at: http://genesdev.cshlp.org/content/3/8/1113.full.html\#ref-list-1

License

Email Alerting

Service

Receive free email alerts when new articles cite this article - sign up in the box at the top right corner of the article or click here.

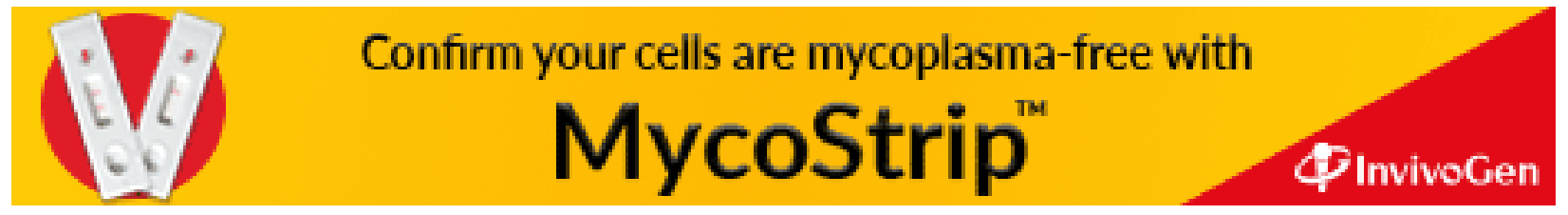

